\title{
ENVIRONMENTALLY BENIGN MITIGATION OF MICROBIOLOGICALLY INFLUENCED CORROSION (MIC)
}

\author{
NINTH QUARTER REPORT
}

(October-December 2003)

Prepared by

John J. Kilbane II

William Bogan

DOE Award No. DE-FC26-01NT41158

GAS TECHNOLOGY INSTITUTE

1700 South Mount Prospect Road

Des Plaines, Illinois 60018

GTI Project 61138 / 30793-35

January 31, 2004 


\section{DISCLAIMER}

This report was prepared as an account of work sponsored by an agency of the United States government. Neither the United States government nor any agency thereof, nor any of their employees, makes any warranty, express or implied, or assumes any legal liability or responsibility for the accuracy, completeness or usefulness of any information, apparatus, product, or process disclosed, or represents that its use would not infringe privately owned rights. Reference herein to any specific commercial

product, process, or service by trade name, trademark, manufacturer, or otherwise does not necessarily constitute or imply its endorsement, recommendation, or favoring by the United States government or any agency thereof. The views and opinions of authors expressed herein do not necessarily state or reflect those of the United States government or any agency thereof. 


\section{LIST OF ACRONYMS}

\begin{tabular}{|c|c|}
\hline Acronyms & Source Term \\
\hline $\mathrm{APB}$ & Acid-Producing Bacteria \\
\hline $\mathrm{BAC}$ & Biologically Active Compound \\
\hline $\mathrm{BCF}$ & Billion Cubic Feet (of natural gas) \\
\hline $\mathrm{COS}$ & Currently Off-the-Shelf (technology or products) \\
\hline EETC & Emerging Energy Technology Campus \\
\hline FERC & Federal Energy Regulatory Commission \\
\hline GTI & Gas Technology Institute \\
\hline GRI & Gas Research Institute \\
\hline $\mathrm{MCF}$ & Million Cubic Feet (of natural gas) \\
\hline $\mathrm{MIC}$ & Microbial Influenced Corrosion \\
\hline MICC & Microbially Influenced Concrete Corrosion \\
\hline MPN & $\begin{array}{l}\text { Most Probable Number (statistical bacterial enumeration } \\
\text { method) }\end{array}$ \\
\hline PI & Principal Investigator \\
\hline $\mathrm{TCF}$ & Trillion Cubic Feet (of natural gas) \\
\hline SRB & Sulfate-Reducing Bacteria \\
\hline HPLC & High Precision Liquid Chromatography \\
\hline ESEM & Environmental Scanning Electron Microscopy \\
\hline
\end{tabular}




\begin{tabular}{|c|c|}
\hline Title: & $\begin{array}{l}\text { Environmentally Benign Mitigation of Microbiologically Influenced } \\
\text { Corrosion (MIC) }\end{array}$ \\
\hline Funding Sources: & U.S. Department of Energy and Gas Research Institute \\
\hline Contract No: & DE-FC26-01NT41158 \\
\hline GTI Project Nos: & $61138 / 30793-35$ \\
\hline $\begin{array}{l}\text { Principal } \\
\text { Investigators: }\end{array}$ & John J. Kilbane II, Ph.D. and William Bogan Ph. D. \\
\hline Report Period: & October 2003 through December 2003 \\
\hline Objective: & $\begin{array}{l}\text { The overall program objective is to develop and evaluate environmentally } \\
\text { benign agents or products that are effective in the prevention, inhibition, } \\
\text { and mitigation of microbially influenced corrosion (MIC) in the internal } \\
\text { surfaces of metallic natural gas pipelines. The goal is to develop one or } \\
\text { more environmentally benign (a.k.a. "green") products that can be applied } \\
\text { to maintain the structure and dependability of the natural gas } \\
\text { infrastructure. }\end{array}$ \\
\hline Approach: & $\begin{array}{l}\text { The technical approach for this quarter included the fractionation of } \\
\text { extracts prepared from several varieties of pepper plants, and using several } \\
\text { solvents, by high performance liquid chromatography (HPLC). A } \\
\text { preliminary determination of antimicrobial activities of the new extracts } \\
\text { and fractions using a growth inhibition assay, and evaluation of the } \\
\text { extracts' ability to inhibit biofilm formation was also performed. }\end{array}$ \\
\hline Results: & $\begin{array}{l}\text { The analysis of multiple extracts of pepper plants and fractions of extracts } \\
\text { of pepper plants obtained by HPLC illustrated that these extracts and } \\
\text { fractions are extremely complex mixtures of chemicals. Gas } \\
\text { chromatography-mass spectrometry was used to identify the chemical } \\
\text { constituents of these extracts and fractions to the greatest degree possible. }\end{array}$ \\
\hline Conclusions: & $\begin{array}{l}\text { Analysis of the chemical composition of various extracts of pepper plants } \\
\text { has illustrated the complexity of the chemical mixtures present, and while } \\
\text { additional work will be performed to further characterize the extracts to } \\
\text { identify bioactive compounds the focus of efforts should now shift to an } \\
\text { evaluation of the ability of extracts to inhibit corrosion in mixed culture } \\
\text { biofilms, and in pure cultures of bacterial types which are known or } \\
\text { believed to be important in corrosion. }\end{array}$ \\
\hline
\end{tabular}




\section{TABLE OF CONTENTS}

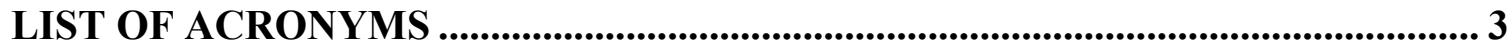

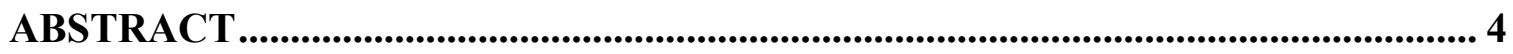

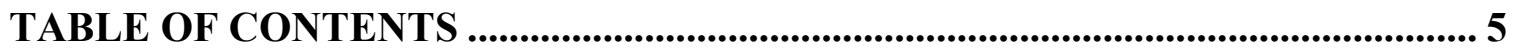

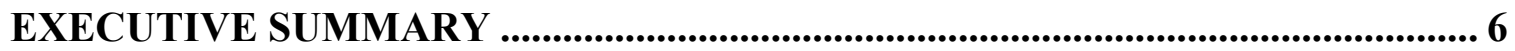

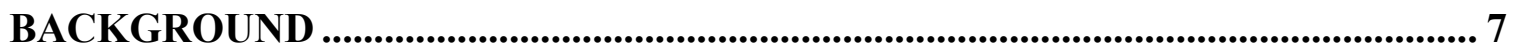

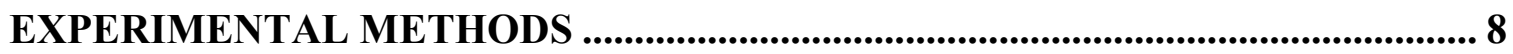

GROWTH INHIBITION (ANTIMICROBIAL) SCREENING ............................ 8 HIGH-PRECISION LIQUID CHROMATOGRAPHY FOR FRACTIONATION OF

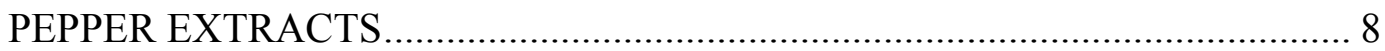

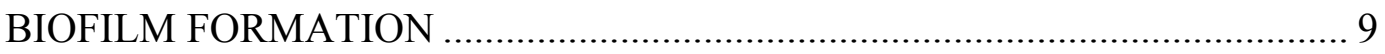

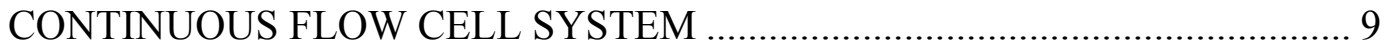

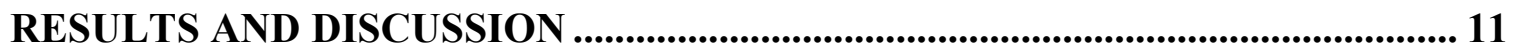

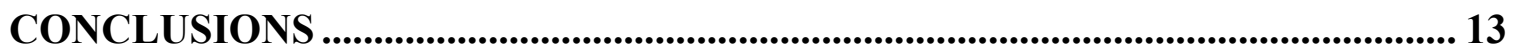

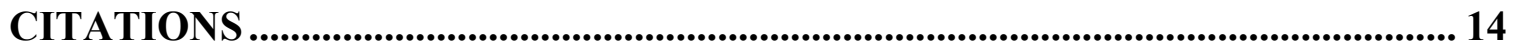

APPENDIX A. GC-MS DATA FROM THE ANALYSIS OF PEPPER PLANT

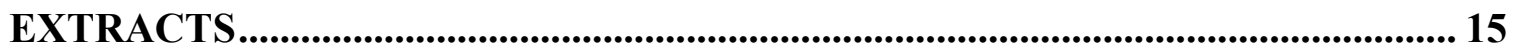




\section{EXECUTIVE SUMMARY}

The main goal of this project is to develop an environmentally benign compound that could prevent and/or control microbially influenced corrosion (MIC) in the interior of metal gas pipelines. The main activities for this quarter were focused on Objectives No. 4) to evaluate pepper oil components to inhibit and mitigate biofilm formation and MIC, and 5) identification and testing of biologically active compounds for biofilm inhibition or mitigation. Extracts from three varieties of Capsicum sp. (such as, Serrano, Habanero and Chile de Arbol ) were obtained by Soxhlet extraction using hexane, methylene chloride, and an extract series using methanol and dimethyl sulfoxide (DMSO) solvent system was also obtained. These extracts were subjected to growth inhibition tests and subsequently to fractionation by HPLC. These extracts and fractions were subjected to Gas Chromatography with Mass Spectrometry (GC-MS) in order to identify chemical components. More fractions will have to be tested both for growth inhibition and biofilm formation while quantification of bioactive compounds is in progress. At this time the available data is not sufficient to allow correlations to be made between bioactivity in the inhibition of bacterial growth or biofilm formation and the presence/concentration of particular chemicals. Future tests will also include mixed cultures and obtaining metal corrosion data. 


\section{BACKGROUND}

The overall objective of this project is to develop, test, and apply environmentally benign agent(s) to control microbial-caused corrosion on the internal surfaces of metal (iron or steel) pipes used for natural gas transmission. The overall hypothesis is that agents exist in nature that inhibit some or all of the steps executed by microorganisms in the formation of biofilm. As biofilm formation is an absolute prerequisite for the initiation and production of microbially influenced corrosion (MIC), blocking biofilm formation or propagation will block or mitigate MIC.

The general approach is to evaluate natural products isolated from plants, and, possibly, animals or microorganisms, for their abilities to block the attachment, physiology, or reproduction of microbial agents that are responsible for MIC. The first natural product to be tested is the oil that can be extracted from the seeds and pods of pepper plants. These plants are members of the Genus Capsicum. The effective components or constituents of this product will then be tested for its environmental impact and effects, effective concentrations, modes of application, and stability against isolated MIC microorganisms under simulated field conditions. A commercially viable agent that aids in MIC control and is environmentally friendly is the ultimate target, with preliminary data to determine commercialization potential and cost benefits.

Since the biocides have been identified, other chemicals that are used by the gas industry as biocides, anti-corrosion agents, drying agents, and coating are being evaluated for interactions. The suppliers have been identified, mainly through NACE, and they are being contacted to obtain samples ( $250 \mathrm{~g}$ to $500 \mathrm{~g}$ ) of their chemicals.

The application of the pepper extract or its identified components using foams has initiated. This "foam pig" concept is accepted by the gas industry and some pipeline service companies are marketing this technology. GTI is looking at commercial foams and foams that are generated internally for a delivery system. 


\section{EXPERIMENTAL METHODS}

\section{Growth Inhibition (Antimicrobial) Screening}

The microdilution assay method (Eloff, 1998) was used to determine the growth inhibition of the pepper components. They were subjected to antimicrobial screening against two sulfate reducing bacteria, D. vulgaris and D. desulfuricans. The test compounds were serially diluted 50\% with sterile distilled water in 96-well microtiter plates. For the inoculum, an overnight bacterial culture was centrifuged at 4,000 rpm for five minutes, washed with a $50 \mathrm{mM}$ phosphate buffered saline, $\mathrm{pH} 6.8$, and the optical density was adjusted at $600 \mathrm{~nm}$ to obtain a final cell concentration of $10^{6} \mathrm{cfu} / \mathrm{mL}$ per well. ATCC \# 1249 Modified Baar's Medium was used as a source of cell nutrients. The multi-well plates were then placed inside a modular anaerobic chamber, purged with nitrogen gas, and incubated at $30^{\circ} \mathrm{C}$ for D. vulgaris and $37^{\circ} \mathrm{C}$ for D. desulfuricans. Optical density at $600 \mathrm{~nm}$ was measured using the MRX II (Dynex Technologies) plate reader from 0 up to 168 hours. Growth inhibition was determined as the test compound limiting turbidity to $<0.05$ absorbance at $600 \mathrm{~nm}$ (Cai et al., 2000). The initially acquired 12 crude extracts were also tested against the denitrifier Comamonas denitrificans using this procedure.

\section{High-Precision Liquid Chromatography for Fractionation of Pepper Extracts}

Pepper extracts were analyzed with High Performance Liquid Chromatography (HPLC) with a Photo Diode Array lamp (PDA) at 285nm. Extracts were received at a $10 \%$ dilution; this was done because the initial extract was too thick to inject, making it impossible to inject 250ul. Using the Supleco Supelcosil LC-18 column $(25 \mathrm{~cm} \times 4.5 \mathrm{~mm}$ $\mathrm{x} 5 \mathrm{um}$ ) the analysis of the extracts was done with a flow rate of $1.0 \mathrm{ml} / \mathrm{min}$ and an initial solvent ratio of $80 \%$ A (0.01M Phosphoric Acid) and 20\% B (HPLC grade Methanol). The flow rate remained the same but the solvent ratio changed with time. The ratio changed gradually to equal $100 \%$ B by 57 min of run time and then slowly went back to the original ratio by $66 \mathrm{~min}$. For each extract myristic, stearic, oleic, palmetic, caffeic, cinnamic, and coumaric acids were qualitatively analyzed along with capsaicin and dihydrocapsaicin. These final two compounds will act as an internal standard and concentration marker for future testing. In addition, this was done to determine how to initiate the next step of the process, which was to fractionate the extracts. 
The Waters Fraction Collector III was used for the fractionating. It is a programmable stand-alone fraction collection module. When running a sample many choices can be made from a simple process of operation such as time, drop, volume, or signal per collection vessel or a more advanced mode can be used such as peak mode, manual, and sampling mode. The time mode was observed to be sufficient.

The collector was set up to collect samples in 13 vials at certain time frames. These samples were collected in test tubes every $5 \mathrm{~min}$. After all extracts were fractionated, they were evaporated to dryness using a mini-evaporator. Upon dryness, the extracts were given to the microbiologist for further analysis.

Gas chromatography - mass spectrometry (GC/MS)was used to determine what compounds were present in pepper plant extracts and fractions.

\section{Biofilm Formation}

The crude extracts were tested against the two sulfate-reducing bacteria for their ability to inhibit biofilm formation. The methods used to look at the effects on biofilm formation and its measurements are discussed in detail by Djordjevic, et al. (2002), Fletcher (1999) and Horn and Jones (2002). The test compounds were incubated with bacterial cells at $10^{8} \mathrm{cfu} / \mathrm{mL}$ (final concentration) and allowed to form biofilm up to 120 hrs. ATCC \# 1249 Modified Baar's Medium was used as a source of cell nutrients. The biofilm assay was done by staining formed/residual biofilm with $1 \%$ crystal violet for 25 minutes, washing the wells with sterile distilled water and dissolving the cell-associated dye by adding $200 \mu \mathrm{L}$ of dimethyl sulfoxide (DMSO) per well (O'Tode and Kolter, 1998). Quantification of the formed biofilm was done by optical density measurement at $600 \mathrm{~nm}$ using the MRX II (Dynex Technologies) plate reader and comparing the results with the untreated biofilm.

\section{Continuous Flow Cell System}

Biofilm formation of D. vulgaris was studied using the continuous flow cell system (Stovall Life Science, Inc., Greensboro, NC). The sterile system consisted mainly of a 3-channel flow cell with individual channel dimensions of $1 \mathrm{~mm} \mathrm{D} \mathrm{x} 4 \mathrm{~mm} \mathrm{~W}$ x 40 $\mathrm{mm} \mathrm{L}$ and the attached microscope coverslip \#1 $(0.13-0.16 \mathrm{~mm}$ thick) that served as the substratum for biofilm growth. The TEST and CONTROL biofilms were grown in separate channels at $37^{\circ} \mathrm{C}$ supplied with Modified Baar's Medium that was prepared 
under $97 \% \mathrm{~N}_{2}$ and $3 \% \mathrm{H}_{2}$. Inocula used were from overnight cultures that were diluted to obtain a final cell concentration of $10^{8} \mathrm{cfu} / \mathrm{mL}$ as measured at $\mathrm{OD}_{600}$. The medium was placed in a water bath and pumped into the system using the IsmaTec low flow peristaltic pump at a flow rate of $3 \mathrm{~mL} / \mathrm{hr}$. The bubble trap near the influent side prevented the air bubbles from reaching the flow cell. After equilibrating the system with the culture media, the flow was stopped and the inoculum $(0.5 \mathrm{~mL})$ was injected at the inlet of each channel. The inoculum for the TEST channel was mixed with crude pepper extract \#5 while that of the CONTROL was suspended in the culture media only. The flow cell was turned upside down to allow the cells to establish on the glass surface (Christensen, et al, 1999; Ramos, et al, 2001). After $1 \mathrm{hr}$, it was inverted to the right-side up position and medium flow was re-started.

Biofilm development for the TEST channel was monitored every 4 hrs for 7 days using light microscopy (Carl Zeiss Axioskop 2 plus, Germany) equipped with time lapse program from Axiovision (Carl Zeiss, Inc.) as the software for image analysis. The Time Lapse software enables the camera to take photos at desired time intervals automatically for the whole duration of the experiment. For the CONTROL channel, photographs were taken manually at the beginning and the end of the run.

To check for cell viability, Live/Dead BacLight (Molecular Probes, Eugene, OR) was used. The biofilms were stained by injecting the dyes near the inlet of the flow cell. Prior to injection, the cells were rinsed with distilled water and both ends of the flow cells were clamped. With epifluorescent microscopy, dead cells appear fluorescent red while live ones are fluorescent green. 


\section{RESULTS AND DISCUSSION}

Several different varieties of pepper plants were extracted several different solvents. The pepper plants tested included Chile de Arbol, Serrano, and Habanero. The extraction solvents tested included hexane, methylene chloride, and a mixture of dimethyl sulfoxide (DMSO) and methanol. As a general means of determining the composition and the "strength" of each extract the amount of capsaicin and dihydrocapsaicin was determined and the results are shown in Table 1.

TABLE 1. AMOUNTS OF CAPSAICIN AND DIHYDROCAPSAICIN IN PEPPER PLANT EXTRACTS

\begin{tabular}{|l|l|l|}
\hline Extract Type & $\begin{array}{l}\text { Capsaicin } \\
\mathrm{mg} / \mathrm{L}\end{array}$ & $\begin{array}{l}\text { Dihydrocapsaicin } \\
\mathrm{mg} / \mathrm{L}\end{array}$ \\
\hline Arbol in Hexane & 1071 & 525 \\
\hline Serrano in Hexane & 642 & 288 \\
\hline Habenero in Hexane & 1215 & 691 \\
\hline $\begin{array}{l}\text { Arbol in Methylene } \\
\text { Chloride }\end{array}$ & 1536 & 678 \\
\hline $\begin{array}{l}\text { Serrano in Methylene } \\
\text { Chloride in Methylene }\end{array}$ & 1613 & 3418 \\
\hline $\begin{array}{l}\text { Habenero in } \\
\text { Chloride }\end{array}$ & 5360 & 103 \\
\hline $\begin{array}{l}\text { Arbol in DMSO/Methanol } \\
\text { Habenero }\end{array}$ & 322 & 103 \\
\hline DMSO/Methanol & 328 & \\
\hline
\end{tabular}

The results in Table 1 indicate that methylene chloride is the most effective solvent as regards the extraction of capsaicin and dihydrocapsaicin from these pepper plants. There is then a range of concentrations of the chemical compounds in these extracts (specifically capsaicin, dihydrocapsaicin and presumable other compounds as well) and directly comparing them with each other as regards bioactivity will make it difficult to interpret the results. To address this the quantity of each pepper extract that was used in microbial growth inhibition and biofilm formation assays was then adjusted, and normalized to the concentration of capsaicin and dihydrocapsaicin in each extract. In 
this way it was hoped that valid comparisons of the bioactivities of each pepper extract could be obtained.

Microbial growth tests were performed with two species of sulfate reducing bacteria: Desulfovibrio vulgaris, and Desulfovibrio desulfuricans. The majority of extracts did not show growth inhibition, as reported last quarter and confirmed with further testing this quarter. However, several of the extracts and fractions derived from the extracts showed growth inhibition of these bacterial cultures. Unexpectedly the methylene chloride extracts did not exhibit the greatest degree of growth inhibition; rather, the hexane extracts yielded more growth inhibition of these two sulfate reducing bacterial cultures.

The extracts were further tested in biofilm formation assays and the results indicated that hexane extracts were more potent inhibitors of biofilm formation by both cultures of Desulfovibrio vulgaris, and Desulfovibrio desulfuricans than the methylene chloride extracts. However, the results of the biofilm formation assays were not as consistent as the results of the growth inhibition assays. Specifically, the hexane extracts from all three pepper species (Chile de Arbol, Serrano, and Habanero) exhibited growth inhibition of the bacterial cultures, but only the hexane extract of the Serrano peppers exhibited biofilm formation inhibition of the bacterial cultures. Since the approximate concentrations of capsaicin and dihydrocapsaicin in these experiments was equivalent, then these results must be due to some other compound(s) present in the pepper plant extracts. To identify what compounds were present in these pepper plant extracts an extensive amount of effort was expended this quarter in performing GC-MS analyses of these pepper plant extracts and fractions of these extracts prepared by HPLC. A large number of the pepper plant extracts and fractions were analyzed by GC-MS and data obtained from these analyses is included as an appendix to this report. The exhaustive analysis of all of the compounds present in these extracts is an enormous job. The computer databases for the analyses of GC-MS data did not allow the identification of all of the peaks/compounds present in these extracts, but a large amount of characterization data was obtained and the work is continuing. 


\section{CONCLUSIONS}

Chemical characterization of the pepper plant extracts has yielded an enormous amount of information. However, in order to correlate the presence of any compounds present in pepper plant extracts with biological activity more data will be needed. Accordingly, activity planned for the next quarter will focus on obtaining data using mixed cultures and pepper plant extracts prepared using hexane. Data that includes actual metal corrosion rates will be crucial to determining the effectiveness of these pepper plant extracts. 


\section{CITATIONS}

Cai, L., Wei, G.X., van der Bijl, P. and Wu, C.D. 2000. Namibian chewing stick, Diospyros lycioides, contains antibacterial compounds against oral pathogens. J. Agric. Food Chem. 48: 909-914.

Christensen, B.B., C. Sternberg, J.B. Andersen, et al. 1999. Molecular tools for the study of biofilm physiology. Methods in Enzymol. 310: 20-42.

Djordjevic, D., M. Wiedmann and L.A. McLandsborough. 2002. Microtiter plate assay for assessment of Listeria monocytogenes biofilm formation. Appl. Environ. Microbiol. 68: $2950-298-58$.

Eloff, J. 1998. A sensitive and quick microplate method to determine the minimal inhibitory concentration of plant extracts for bacteria. Planta Medica 64: 711-713.

Fletcher, M. 1999. Biofilms and Biocorrosion, p. 704-714. In A.L. Demain, J.E. Davies, R.M. Atlas, D.H. Sherman, G. Cohen, R.C. Willson, C.L. Hershberger, J.H.D. Wu, and W.-S. Hu (eds.), Manual of Industrial Microbiology and Biotechnology $2^{\text {nd }}$ Edition. ASM Press. Washington, DC.

Horn, J. and D. Jones. 2002. Microbially influenced corrosion: perspectives and approaches, p. 1072-1083. In C.J. Hurst, R.L. Crawford, M.J. McInerney, G.R. Knudsen, and L.D. Stetzenbach (eds.), Manual of Environmental Microbiology, $2^{\text {nd }}$ Edition. ASM Press. Washington DC.

O’Tode, G.A. and R. Kolter. 1998. The initiation of biofilm formation in Pseudomonas fluorescens WCS365 proceedings va multiple convergent signaling pathways: a genetic analysis. Mol. Microbiol. 28: 41-461.

Ramos, C., T.R. Light, C. Sternberg, et al. 2001. Monitoring bacterial growth activity in biofilms from laboratory flow chambers, plant rhizosphere and animal intestine. Methods in Enzymol. 337: 21-42.

Stoodley, L.H., J.C. Rayner, P. Stoodley, and H.M. Lappin-Scott. 1999. Establishment of experimental biofilms using the modified Robbins device and flow cells. In: Environmental monitoring of bacteria. Humana Press Inc., Totowa, NJ. pp.307-319. 
APPENDIX A. GC-MS DATA FROM THE ANALYSIS OF PEPPER PLANT EXTRACTS 
Data File:

Curr Data Path:

Acquisition Date:

Run Time (min):

Vial:

Inj Vol $(\mu \mathrm{L})$ :

Scans:

Low Mass (m/z):

High Mass ( $\mathrm{m} / \mathrm{z})$ :

Inst Method:

Proc Method:

RT: $0.00-35.01$ SM : $7 G$

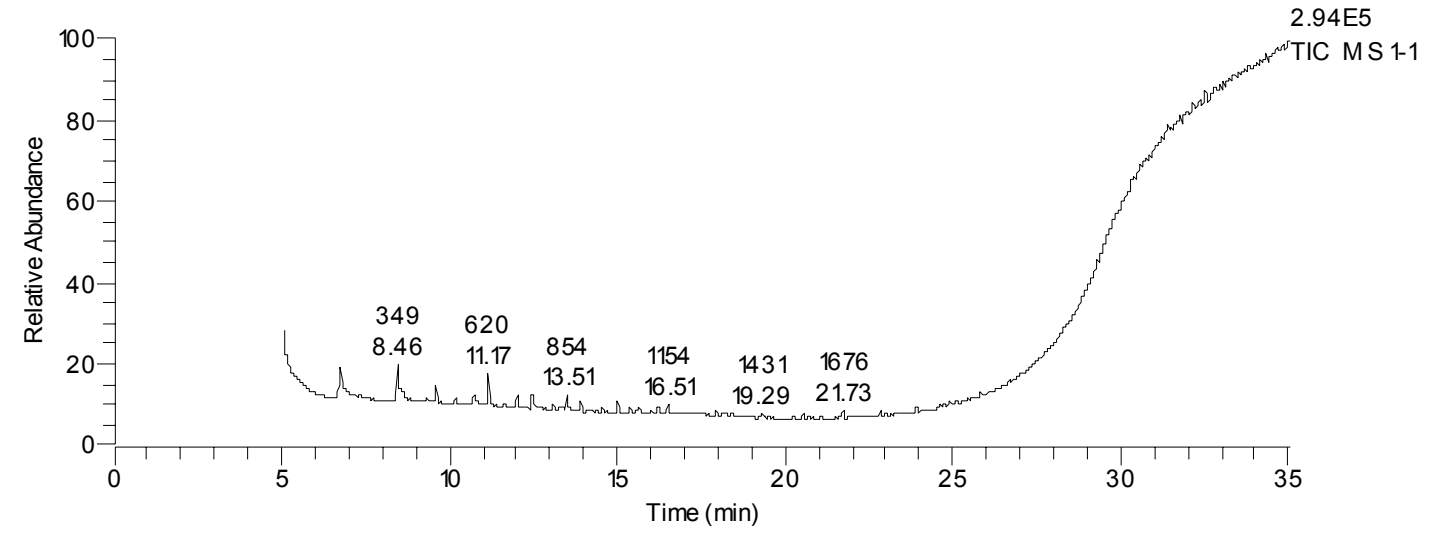

D:\Xcalibur\Data $\backslash$ GemmaH $\backslash$ peppers $100703 \backslash$

10/07/03 17:32:34

29.97

23

2.00

3064

35.00

550.00

D:|Xcalibur $\backslash$ methods $\mid$ pepper_PTV.meth

D: IXcalibur $\backslash$ methods $\backslash q u a l i t a t i v e I D$
$\mathrm{NL}$

2.94E5

\begin{tabular}{|c|c|c|}
\hline RT & Peak Area & Area \% \\
\hline 5.07 & 5653 & 0.59 \\
\hline 6.74 & 284537 & 29.62 \\
\hline 8.47 & 184256 & 19.18 \\
\hline 9.32 & 3728 & 0.39 \\
\hline 9.59 & 35812 & 3.73 \\
\hline 10.19 & 9520 & 0.99 \\
\hline 10.74 & 48334 & 5.03 \\
\hline 11.17 & 55050 & 5.73 \\
\hline 11.63 & 872 & 0.09 \\
\hline 12.02 & 16744 & 1.74 \\
\hline 12.47 & 40018 & 4.17 \\
\hline 13.08 & 13170 & 1.37 \\
\hline 13.35 & 19271 & 2.01 \\
\hline 13.51 & 37686 & 3.92 \\
\hline 13.75 & 2189 & 0.23 \\
\hline 13.91 & 16235 & 1.69 \\
\hline 14.39 & 1388 & 0.14 \\
\hline 14.56 & 6367 & 0.66 \\
\hline 15.02 & 22611 & 2.35 \\
\hline 15.36 & 9566 & 1.00 \\
\hline 15.64 & 18611 & 1.94 \\
\hline
\end{tabular}




\begin{tabular}{|c|c|c|}
\hline 16.23 & 11236 & 1.17 \\
\hline 16.51 & 13816 & 1.44 \\
\hline 17.96 & 4456 & 0.46 \\
\hline 18.21 & 5830 & 0.61 \\
\hline 19.30 & 7645 & 0.80 \\
\hline 20.55 & 7821 & 0.81 \\
\hline 20.68 & 4377 & 0.46 \\
\hline 21.73 & 10669 & 1.11 \\
\hline 22.09 & 1647 & 0.17 \\
\hline 22.86 & 8091 & 0.84 \\
\hline 23.01 & 1235 & 0.13 \\
\hline 23.91 & 9105 & 0.95 \\
\hline 24.77 & 13101 & 1.36 \\
\hline 24.90 & 9177 & 0.96 \\
\hline 25.46 & 3563 & 0.37 \\
\hline 25.83 & 4811 & 0.50 \\
\hline 26.70 & 1917 & 0.20 \\
\hline 27.52 & 5476 & 0.57 \\
\hline 27.77 & 4981 & 0.52 \\
\hline
\end{tabular}

\begin{tabular}{|c|c|c|c|c|c|c|}
\hline $\mathrm{T}$ & Name & I & rob. & $\begin{array}{l}\text { F } \\
\text { ormula }\end{array}$ & W & $\begin{array}{ll} & \mathrm{Ca} \\
\mathrm{s} \# & \end{array}$ \\
\hline 0.19 & 1H-Indene, 1-methylene- & 15 & 3.32 & $10 \mathrm{H} 8$ & 28 & $71-84-3$ \\
\hline 0.19 & Naphthalene & 10 & 8.79 & $\begin{array}{ll} & \mathrm{C} \\
10 \mathrm{H} 8 & \end{array}$ & 28 & $20-3$ \\
\hline 0.19 & NAPHTHALENE DB5-826 & 05 & 5.15 & & & $\mathrm{~N}$ \\
\hline 0.19 & 4-Phenylbut-3-ene-1-yne & 97 & 1.30 & $10 \mathrm{H} 8$ & 28 & $\mathrm{~N}$ \\
\hline 0.19 & AZULENE DB5-1140 & 96 & 0.86 & & & A \\
\hline
\end{tabular}

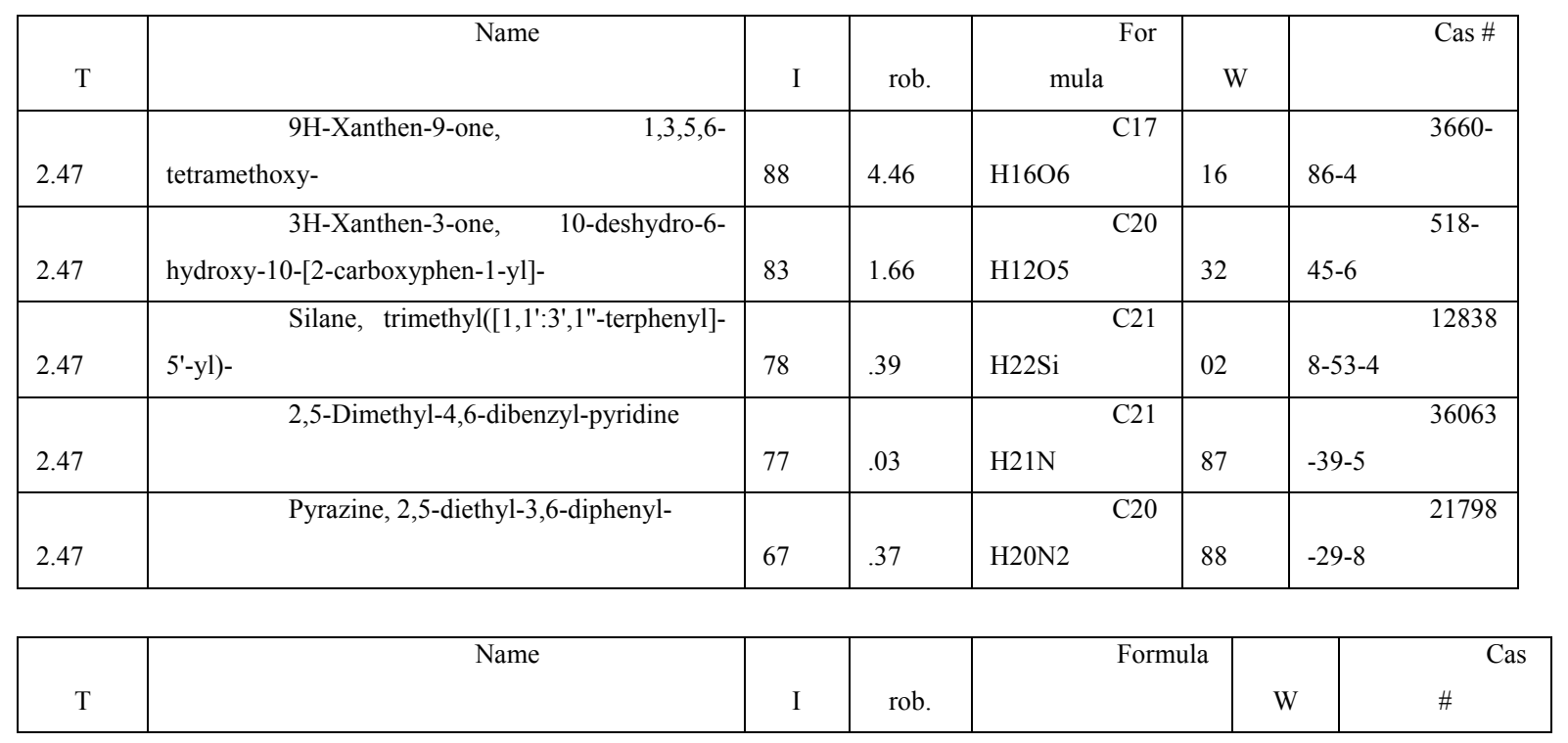




\begin{tabular}{|c|c|c|c|c|c|c|}
\hline 5.36 & Benzenesulfonamide, N-butyl- & 51 & 5.28 & $\begin{array}{ll}\mathrm{C} 10 \mathrm{H} 15 \\
\mathrm{NO} 2 \mathrm{~S}\end{array}$ & 13 & $2-362$ \\
\hline 5.36 & $\begin{array}{l}\text { 1,3,5-Trisbenzene-sulphonyl- } \\
\text { hexahydro-1,3,5-triazine }\end{array}$ & 22 & .59 & $\begin{array}{ll}\mathrm{C} 21 \mathrm{H} 21 \\
\mathrm{~N} 3 \mathrm{O} 6 \mathrm{~S} 3\end{array}$ & 07 & NA \\
\hline 5.36 & Benzenesulfonyl azide & 21 & .45 & $\mathrm{O} 2 \mathrm{~S}$ & 83 & $938-$ \\
\hline 5.36 & Diphenyl ether & 03 & .78 & $\mathrm{C} 12 \mathrm{H} 10$ & 70 & 101- \\
\hline 5.36 & $\begin{array}{l}\text { 5-(Phenylsulphonyl)dihydro-1,3,5- } \\
\text { dioxazine }\end{array}$ & 98 & .43 & C9H11N & 29 & 21-07-9 \\
\hline
\end{tabular}

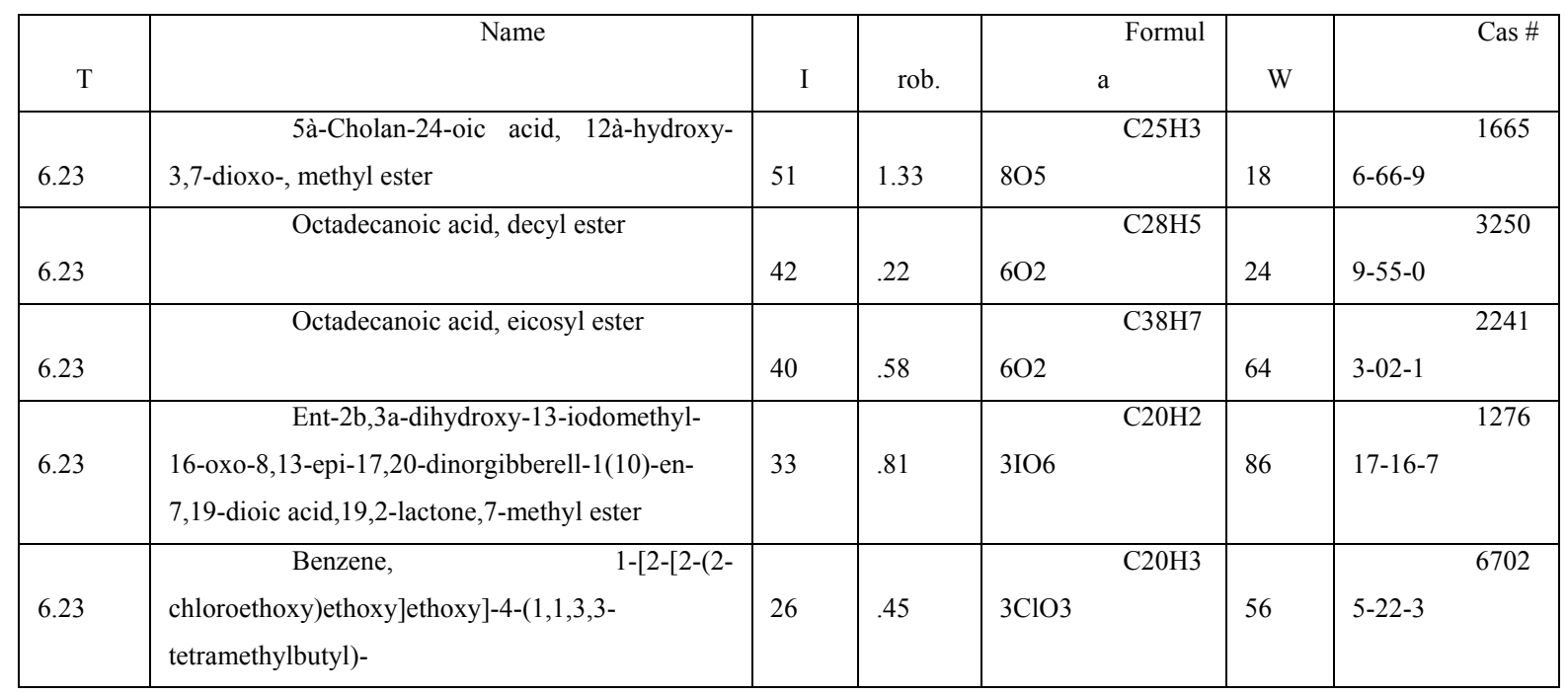

\begin{tabular}{|c|c|c|c|c|c|c|c|}
\hline $\mathrm{T}$ & Name & I & rob. & Formula & W & & Cas \# \\
\hline 8.21 & $\begin{array}{l}\text { 4aà,4bá-Gibbane-1,1,10á-tricarboxylic } \\
\text { acid, 4a,7-dihydroxy-8-methylene-, 1à,4a-lactone, } \\
\text { dimethyl ester }\end{array}$ & 07 & 1.08 & $\mathrm{C} 21 \mathrm{H} 26$ & 90 & $0-95-8$ & 1845 \\
\hline 8.21 & $\begin{array}{l}\text { 9-Borabicyclo[3.3.1]nonane, 9-[[3-[2- } \\
\text { (9-borabicyclo[3.3.1]non-9-yloxy)phenyl]-1- } \\
\text { thioxopropyl]thio]- }\end{array}$ & 95 & .38 & $\mathrm{C} 25 \mathrm{H} 36$ & 38 & $59-23-2$ & 1397 \\
\hline 8.21 & $\begin{array}{l}\text { Ent-3a,10-dihydroxy-13-iodomethyl- } \\
\text { 16-oxo-8,13-epi-17,20-dinorgibberell-1-en-7,19- } \\
\text { dioic acid,19,10-lactone,7-methyl ester }\end{array}$ & 94 & .09 & $\mathrm{C} 20 \mathrm{H} 23 \mathrm{I}$ & 86 & $28-84-3$ & 1164 \\
\hline 8.21 & $\begin{array}{l}\text { Pregn-16-ene-11,14,18,20-tetrol, } 3,9- \\
\text { epoxy-3-methoxy-, } \\
\text { (3à,5á,11à,14á,20R)- }\end{array}$ & 85 & .15 & $\mathrm{C} 26 \mathrm{H} 38$ & 78 & $4-56-0$ & 3877 \\
\hline 8.21 & $\begin{array}{l}\text { 1,1'-Biphenyl, 4,2',3',4'-tetramethoxy-6- } \\
{[\mathrm{N} \text {-methyl-N-acetylaminomethyl] }}\end{array}$ & 84 & .95 & $\mathrm{C} 20 \mathrm{H} 25$ & 59 & & NA \\
\hline
\end{tabular}


Data File: 1-6

Curr Data Path:

Acquisition Date:

Run Time (min):

Vial:

Inj Vol $(\mu \mathrm{L})$ :

Scans:

Low Mass $(\mathrm{m} / \mathrm{z})$ :

High Mass ( $\mathrm{m} / \mathrm{z})$ :

Inst Method:

Proc Method:

RT: $0.00-35.03$ SM : $7 G$

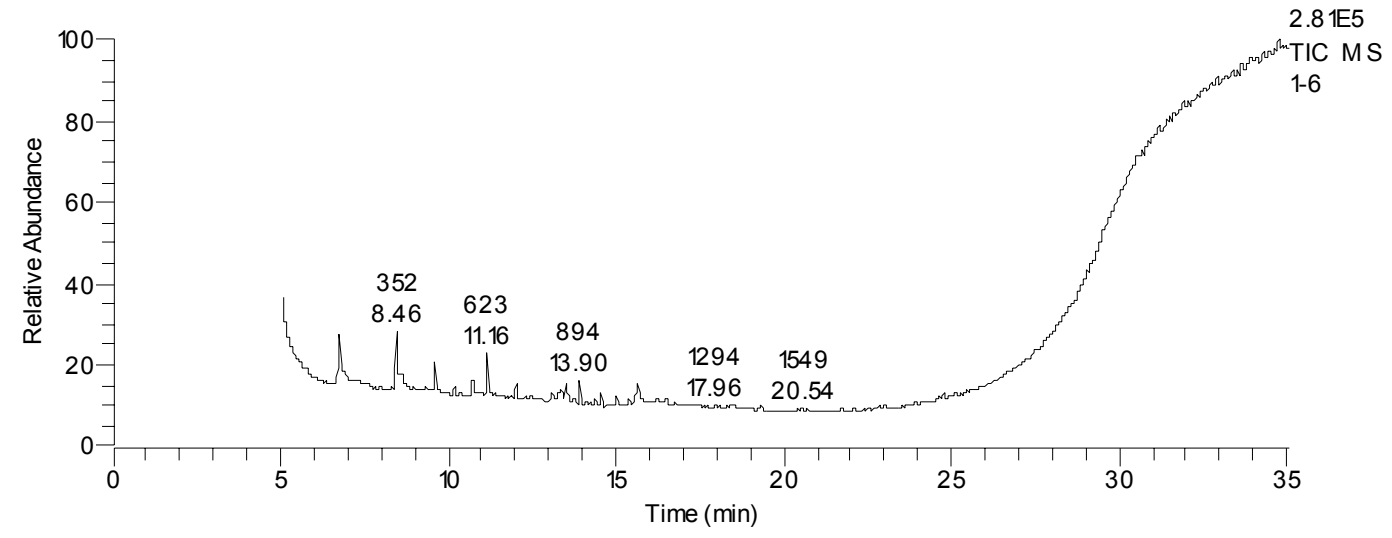

D:|Xcalibur|Data $\backslash G e m m a H \backslash p e p p e r s 100703 \backslash$

10/07/03 18:20:24

29.98

24

2.00

3049

35.00

550.00

D:|Xcalibur $\backslash$ methods $\mid$ pepper_PTV.meth

D: $\mid$ Xcalibur $\backslash$ methods $\backslash$ qualitativeID

\begin{tabular}{|c|c|c|}
\hline RT & Peak Area & Area \% \\
\hline 6.73 & 352609 & 24.80 \\
\hline 8.46 & 264802 & 18.63 \\
\hline 9.31 & 1615 & 0.11 \\
\hline 9.58 & 56460 & 3.97 \\
\hline 10.19 & 10897 & 0.77 \\
\hline 10.73 & 56421 & 3.97 \\
\hline 11.16 & 98980 & 6.96 \\
\hline 12.02 & 21556 & 1.52 \\
\hline 12.49 & 8547 & 0.60 \\
\hline 12.78 & 1958 & 0.14 \\
\hline 13.10 & 37165 & 2.61 \\
\hline 13.34 & 69365 & 4.88 \\
\hline 13.52 & 65975 & 4.64 \\
\hline 13.74 & 7098 & 0.50 \\
\hline 13.91 & 34951 & 2.46 \\
\hline 14.38 & 9030 & 0.64 \\
\hline 14.56 & 22063 & 1.55 \\
\hline 15.00 & 24415 & 1.72 \\
\hline 15.36 & 9213 & 0.65 \\
\hline 15.64 & 131726 & 9.27 \\
\hline 15.98 & 15211 & 1.07 \\
\hline
\end{tabular}




\begin{tabular}{|l|l|l|}
\hline 16.23 & 38719 & 2.72 \\
\hline 16.52 & 14714 & 1.04 \\
\hline 17.96 & 2740 & 0.19 \\
\hline 18.43 & 12743 & 0.90 \\
\hline 19.29 & 3510 & 0.25 \\
\hline 20.54 & 4367 & 0.31 \\
\hline 21.74 & 6117 & 0.43 \\
\hline 22.09 & 1356 & 0.10 \\
\hline 22.86 & 2431 & 0.17 \\
\hline 23.01 & 1797 & 0.13 \\
\hline 23.92 & 3730 & 0.26 \\
\hline 24.77 & 15658 & 1.10 \\
\hline 25.12 & 2454 & 0.17 \\
\hline 25.45 & 4526 & 0.32 \\
\hline 25.84 & 657 & 0.05 \\
\hline 27.78 & 6052 & 0.43 \\
\hline
\end{tabular}

\begin{tabular}{|c|c|c|c|c|c|c|}
\hline $\mathrm{T}$ & Name & I & rob. & Formula & W & Cas \\
\hline 5.36 & Benzenesulfonamide, N-butyl- & 06 & 6.47 & $\mathrm{C} 10 \mathrm{H} 15$ & 13 & $2-862$ \\
\hline 5.36 & Benzene, [(trifluoromethyl)sulfonyl]- & 51 & .24 & C7H5F3 & 10 & 426 \\
\hline 5.36 & Diphenyl ether & 47 & .89 & $\mathrm{C} 12 \mathrm{H} 10$ & 70 & 101 \\
\hline 5.36 & Benzene, (ethylsulfonyl)- & 44 & .67 & $\mathrm{O} 2 \mathrm{~S}$ & 70 & $70-2$ \\
\hline 5.36 & $\begin{array}{l}\text { 5-(Phenylsulphonyl)dihydro-1,3,5- } \\
\text { dioxazine }\end{array}$ & 33 & .15 & $\mathrm{NO} 4 \mathrm{~S}$ & 29 & 21-07-9 \\
\hline
\end{tabular}

\begin{tabular}{|c|c|c|c|c|c|c|c|}
\hline $\mathrm{T}$ & Name & I & rob. & Formula & W & & Cas \# \\
\hline 5.98 & $\begin{array}{l}\text { 3-[18-(3-Hydroxy-propyl)-3,3,7,12,17- } \\
\text { pentamethyl-2,3,22,24-tetrahydro-porphin-2- } \\
\text { yl]propan-1-ol }\end{array}$ & 57 & 1.27 & C31H38N4 & 98 & & NA \\
\hline 5.98 & $\begin{array}{l}\text { Tungsten, pentacarbonyl(4,5-diethyl- } \\
\text { 2,2,3-trimethyl-1-phenyl-1-phospha-2-sila-5- } \\
\text { boracyclohex-3-ene-P1)-, (oc-6-22)- }\end{array}$ & 41 & 8.01 & $\mathrm{C} 21 \mathrm{H} 26 \mathrm{BO}$ & 12 & $72-51-3$ & 1187 \\
\hline 5.98 & 4'-Apo-á,.psi.-carotenoic acid & 18 & .57 & $\mathrm{C} 35 \mathrm{H} 46 \mathrm{O} 2$ & 98 & $88-4$ & $2468-$ \\
\hline 5.98 & $\begin{array}{c}\text { Hexadecanoic } \quad \text { acid, } \\
\text { N,N- } \\
\text { bis }[(\text { methylcarboxy)ethyl-2-(2-butoxyethoxy) }]-\end{array}$ & 12 & .17 & $\mathrm{C} 36 \mathrm{H} 69 \mathrm{NO}$ & 59 & & NA \\
\hline 5.98 & $\begin{array}{l}\text { 9,19-Cyclolanostane-6,7-dione, } \\
\text { acetoxy- }\end{array}$ & 10 & .76 & $\mathrm{C} 32 \mathrm{H} 50 \mathrm{O} 4$ & 98 & & NA \\
\hline
\end{tabular}

\begin{tabular}{|c|r|r|r|r|r|r|}
\hline $\mathrm{T}$ & Name & $\mathrm{I}$ & rob. & a & $\mathrm{W}$ & Cas \# \\
\hline & & & C31H3 & & NA \\
\hline
\end{tabular}




\begin{tabular}{|c|c|c|c|c|c|c|}
\hline 6.23 & $\begin{array}{l}\text { pentamethyl-2,3,22,24-tetrahydro-porphin-2- } \\
\text { yl]propan-1-ol }\end{array}$ & 28 & 9.55 & $8 \mathrm{~N} 4 \mathrm{O} 2$ & 98 & \\
\hline 6.23 & $\begin{array}{l}\text { 5à-Cholan-24-oic acid, 12à-hydroxy-3,7- } \\
\text { dioxo-, methyl ester }\end{array}$ & 26 & 8.03 & $\mathrm{C} 25 \mathrm{H} 3$ & 18 & 6-66-9 \\
\hline 6.23 & $\begin{array}{l}\text { Ent-2b,3a-dihydroxy-13-iodomethyl-16- } \\
\text { oxo-8,13-epi-17,20-dinorgibberell-1(10)-en-7,19- } \\
\text { dioic acid,19,2-lactone,7-methyl ester }\end{array}$ & 10 & 0.38 & $\mathrm{C} 20 \mathrm{H} 2$ & 86 & $17-16-7$ \\
\hline 6.23 & $\begin{array}{l}\text { (5á,13á)3,19-Epoxyandrost-8-ene, } \\
\text { acetoxy-3-methoxy-4,4,13-trimethyl- }\end{array}$ & 03 & .95 & $\mathrm{C} 25 \mathrm{H} 3$ & 02 & NA \\
\hline 6.23 & $\begin{array}{cc}\text { Hexadecanoic } & \text { acid, } \\
\text { bis }[(\text { methylcarboxy)ethyl-2-(2-butoxyethoxy) }]-\end{array}$ & 00 & .03 & 9NO9 & 59 & NA \\
\hline
\end{tabular}


Data File:

Curr Data Path:

Acquisition Date:

Run Time (min):

Vial:

Inj Vol $(\mu \mathrm{L})$ :

Scans:

Low Mass $(\mathrm{m} / \mathrm{z})$ :

High Mass ( $\mathrm{m} / \mathrm{z})$ :

Inst Method:

Proc Method:

RT: $0.00-35.03$ SM : $7 G$

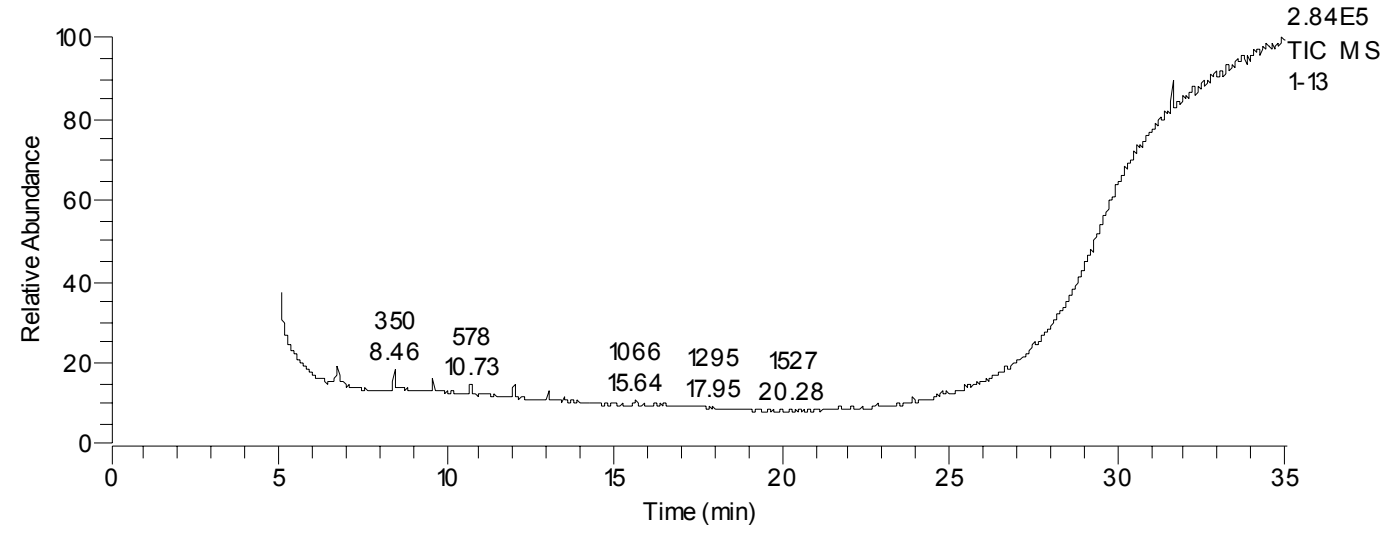

D:|Xcalibur|Data $\backslash G e m m a H \backslash p e p p e r s 100703 \backslash$

10/07/03 19:11:20

29.99

25

2.00

3058

35.00

550.00

D:|Xcalibur $\backslash$ methods $\mid$ pepper_PTV.meth

D: $|X c a l i b u r| m e t h o d s \backslash q u a l i t a t i v e I D$
$84 \mathrm{E} 5$

\begin{tabular}{|c|c|c|}
\hline RT & Peak Area & Area \% \\
\hline 6.35 & 2496 & 0.49 \\
\hline 6.54 & 7934 & 1.57 \\
\hline 6.73 & 98371 & 19.46 \\
\hline 8.46 & 59647 & 11.80 \\
\hline 8.64 & 18411 & 3.64 \\
\hline 8.84 & 20349 & 4.03 \\
\hline 9.18 & 9376 & 1.85 \\
\hline 9.36 & 14293 & 2.83 \\
\hline 9.58 & 46819 & 9.26 \\
\hline 9.88 & 9406 & 1.86 \\
\hline 10.18 & 6218 & 1.23 \\
\hline 10.73 & 16732 & 3.31 \\
\hline 11.15 & 1515 & 0.30 \\
\hline 11.76 & 1627 & 0.32 \\
\hline 12.02 & 18120 & 3.58 \\
\hline 13.05 & 18656 & 3.69 \\
\hline 13.34 & 1245 & 0.25 \\
\hline 13.51 & 12056 & 2.38 \\
\hline 13.73 & 4828 & 0.96 \\
\hline 13.90 & 4683 & 0.93 \\
\hline 14.39 & 2437 & 0.48 \\
\hline
\end{tabular}




\begin{tabular}{|c|c|c|}
\hline 15.01 & 4575 & 0.90 \\
\hline 15.64 & 12236 & 2.42 \\
\hline 16.21 & 836 & 0.17 \\
\hline 16.52 & 5398 & 1.07 \\
\hline 16.71 & 1582 & 0.31 \\
\hline 16.91 & 2791 & 0.55 \\
\hline 17.10 & 1904 & 0.38 \\
\hline 17.43 & 3707 & 0.73 \\
\hline 17.96 & 1306 & 0.26 \\
\hline 19.29 & 1983 & 0.39 \\
\hline 20.01 & 334 & 0.07 \\
\hline 20.54 & 3840 & 0.76 \\
\hline 21.74 & 4860 & 0.96 \\
\hline 22.10 & 822 & 0.16 \\
\hline 22.86 & 7586 & 1.50 \\
\hline 23.92 & 7151 & 1.41 \\
\hline 24.77 & 18955 & 3.75 \\
\hline 24.89 & 10634 & 2.10 \\
\hline 25.45 & 7093 & 1.40 \\
\hline 25.58 & 6555 & 1.30 \\
\hline 25.83 & 4082 & 0.81 \\
\hline 26.25 & 1827 & 0.36 \\
\hline 26.70 & 7046 & 1.39 \\
\hline 26.89 & 2891 & 0.57 \\
\hline 27.53 & 3499 & 0.69 \\
\hline 27.77 & 6840 & 1.35 \\
\hline
\end{tabular}

\begin{tabular}{|c|c|c|c|c|c|c|}
\hline $\mathrm{T}$ & Name & I & rob. & Form & W & \# ${ }^{2}$ Cas \\
\hline .88 & $\begin{array}{l}\text { (22S)-21-Acetoxy-6à,11á-dihydroxy- } \\
\text { 16à,17à-propylmethylenedioxypregna-1,4-diene- } \\
\text { 3,20-dione }\end{array}$ & 18 & 1.63 & $\mathrm{C} 27 \mathrm{H}$ & 88 & $89-66-3$ \\
\hline .88 & $\begin{array}{l}\text { (22S)-6à,11á,21-Trihydroxy-16à,17à- } \\
\text { propylmethylenedioxypregna-1,4-diene-3,20-dione }\end{array}$ & 97 & .20 & $34 \mathrm{O} 7 \quad \mathrm{C} 25 \mathrm{H}$ & 46 & $61-53-1$ \\
\hline .88 & $\begin{array}{l}\text { 17-(1,5-Dimethylhexyl)-10,13- } \\
\text { dimethyl-3- } \\
\text { styrylhexadecahydrocyclopenta[a]phenanthren-2- } \\
\text { one }\end{array}$ & 96 & .84 & 520 & 88 & NA \\
\hline .88 & $\begin{array}{l}\text { (22S)-6á,1 1á,21-Trihydroxy-16à,17à- } \\
\text { propylmethylenedioxypregna-1,4-diene-3,20-dione }\end{array}$ & 93 & .81 & $34 \mathrm{O} 7$ & 46 & NA \\
\hline .88 & $\begin{array}{l}\text { 5H-Cyclopropa[3,4]benz[1,2-e]azulen- } \\
\text { 5-one, } \\
\text { 3,[(acetyloxy)methyl]- } \\
\text { 1,1a,1b,2,3,4,4a,7a,7b,8,9,9a-dodecahydracetyloxy)- } \\
\text { dihydroxy-1,1,6,8-tetramethyl-, } \\
\text { (1aà,1bá,2à,3á,4aá,7aà,7bà,8à,9á,9aà)]- }\end{array}$ & 88 & .29 & 40013 & 08 & $73-25-2$ \\
\hline
\end{tabular}




\begin{tabular}{|c|c|c|c|c|c|c|}
\hline $\mathrm{T}$ & Name & I & rob. & $\begin{array}{l}\text { Formul } \\
\text { a }\end{array}$ & W & as \# \\
\hline 0.18 & AZULENE DB5-1140 & 29 & 5.29 & & & A \\
\hline 0.18 & Naphthalene & 26 & 3.51 & $\mathrm{C} 10 \mathrm{H} 8$ & 28 & $\begin{array}{lr} & 9 \\
1-20-3 & \end{array}$ \\
\hline 0.18 & 1H-Indene, 1-methylene- & 16 & .53 & $\mathrm{C} 10 \mathrm{H} 8$ & 28 & $471-84-3$ \\
\hline 0.18 & NAPHTHALENE DB5-826 & 11 & .68 & & & A \\
\hline 0.18 & $\begin{array}{l}\text { 2á,4a-Epoxymethylphenanthrene-7- } \\
\text { methanol, 1,1-dimethyl-2-methoxy-8-(1,3-dithiin- } \\
\text { 2-ylidene)methyl-1,2,3,4,4a,4b,5,6,7,8,8a,9- } \\
\text { dodecahydro-, acetate }\end{array}$ & 06 & .19 & $8 \mathrm{O} 4 \mathrm{~S} 2$ & 90 & A \\
\hline
\end{tabular}

\begin{tabular}{|c|c|c|c|c|c|c|}
\hline $\mathrm{T}$ & Name & I & rob. & Form & W & Cas \\
\hline 1.76 & $\begin{array}{l}\text { Pregn-16-ene-11,14,18,20-tetrol, 3,9- } \\
\text { epoxy-3-methoxy-, } \\
\text { (3à,5á,11à,14á,20R)- }\end{array}$ & 23 & 0.65 & $\mathrm{C} 26 \mathrm{H}$ & 78 & $74-56-0$ \\
\hline 1.76 & $\begin{array}{l}\text { 9-Desoxo-9x-hydroxy-7-ketoingol } \\
\text { 3,8,9,12-tetraacetate }\end{array}$ & 19 & .00 & 38010 & 34 & NA \\
\hline 1.76 & 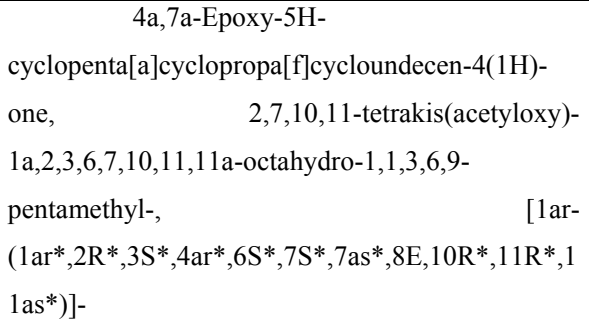 & 10 & .53 & 38010 & 34 & $06-02-6$ \\
\hline 1.76 & $\begin{array}{l}\text { 9-Desoxo-9-x-acetoxy-3-desoxy- } \\
\text { 7.8.12-tri-O-acetylingol-3-one }\end{array}$ & 09 & .28 & 38010 & 34 & NA \\
\hline 1.76 & $\begin{array}{c}\text { Pregn-16-en-20-one, } \\
\text { bis(acetyloxy)-3,9-epoxy-3-methoxy-, (3à,5á,11à)- }\end{array}$ & 05 & .30 & 3607 & 60 & $84-39-5$ \\
\hline
\end{tabular}

\begin{tabular}{|c|c|c|c|c|c|c|}
\hline $\mathrm{T}$ & Name & I & rob. & la Formu & W & $\begin{array}{ll} & \text { Cas } \\
\# & \end{array}$ \\
\hline 0.01 & $\begin{array}{l}\text {.psi.,.psi.-Carotene, } 3,3^{\prime}, 4,4^{\prime}- \\
\text { tetradehydro-1,1',2,2'-tetrahydro-1-hydroxy-1'- } \\
\text { methoxy- }\end{array}$ & 71 & .96 & $\mathrm{C} 41 \mathrm{H}$ & 82 & $76-79-7$ \\
\hline 0.01 & 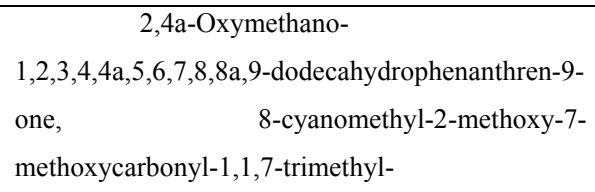 & 69 & .26 & $31 \mathrm{NO5}$ & 01 & NA \\
\hline 0.01 & $\begin{array}{l}\text {.psi..,psi.-Carotene, } 3,4 \text {-didehydro- } \\
1,2,7^{\prime}, 8^{\prime} \text {-tetrahydro-1-methoxy-2-oxo- }\end{array}$ & 66 & .30 & $\mathrm{C} 41 \mathrm{H}$ & 82 & $36-70-9$ \\
\hline 0.01 & $\begin{array}{l}\text { 9-Desoxo-9-x-acetoxy-3,8,12-tri-O- } \\
\text { acetylingol }\end{array}$ & 58 & .44 & $40 \mathrm{O} 10$ & 36 & NA \\
\hline 0.01 & $\begin{array}{l}\text { 17-(1,5-Dimethylhexyl)-10,13- } \\
\text { dimethyl-3- }\end{array}$ & 56 & .02 & $\mathrm{C} 35 \mathrm{H}$ & 88 & NA \\
\hline
\end{tabular}




\begin{tabular}{|l|l|l|l|l|l|l|}
\hline & $\begin{array}{l}\text { styrylhexadecahydrocyclopenta[a]phenanthren-2- } \\
\text { one }\end{array}$ & & & & & \\
\hline
\end{tabular}


Data File:

Curr Data Path:

Acquisition Date:

Run Time (min):

Vial:

Inj Vol $(\mu \mathrm{L})$ :

Scans:

Low Mass (m/z):

High Mass ( $\mathrm{m} / \mathrm{z})$ :

Inst Method:

Proc Method:

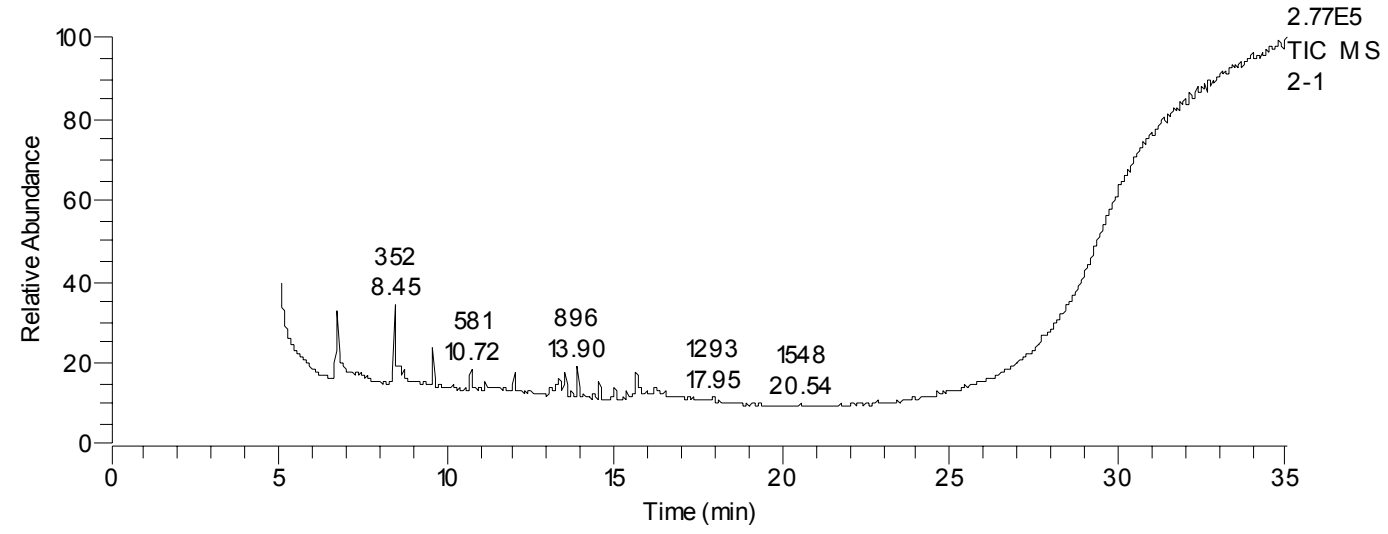

10/07/03 20:02:38

29.96

26

2.00

3039

35.00

550.00

D:|Xcalibur $\backslash$ methods $\mid$ pepper_PTV.meth

D: $|X c a l i b u r| m e t h o d s \backslash q u a l i t a t i v e I D$
D:|Xcalibur|Data $\backslash G e m m a H \backslash p e p p e r s 100703 \backslash$
RT: $0.00-35.00$ SM : 7G

$\mathrm{NL}$ 7765 


\begin{tabular}{|l|l|l|}
\hline 15.01 & 32223 & 1.93 \\
\hline 15.36 & 11203 & 0.67 \\
\hline 15.65 & 168871 & 10.13 \\
\hline 15.97 & 30934 & 1.86 \\
\hline 16.23 & 79134 & 4.75 \\
\hline 16.51 & 21353 & 1.28 \\
\hline 17.95 & 2720 & 0.16 \\
\hline 19.29 & 2915 & 0.17 \\
\hline 20.54 & 1251 & 0.08 \\
\hline 21.75 & 831 & 0.05 \\
\hline 22.10 & 1388 & 0.08 \\
\hline 22.86 & 679 & 0.04 \\
\hline 24.77 & 11771 & 0.71 \\
\hline 25.45 & 4519 & 0.27 \\
\hline 27.79 & 8287 & 0.50 \\
\hline
\end{tabular}


Data File: 2-6

Curr Data Path:

Acquisition Date:

Run Time (min):

Vial:

Inj Vol $(\mu \mathrm{L})$ :

Scans:

Low Mass (m/z):

High Mass ( $\mathrm{m} / \mathrm{z})$ :

Inst Method:

Proc Method:

RT: $0.00-35.01$ SM : $7 G$

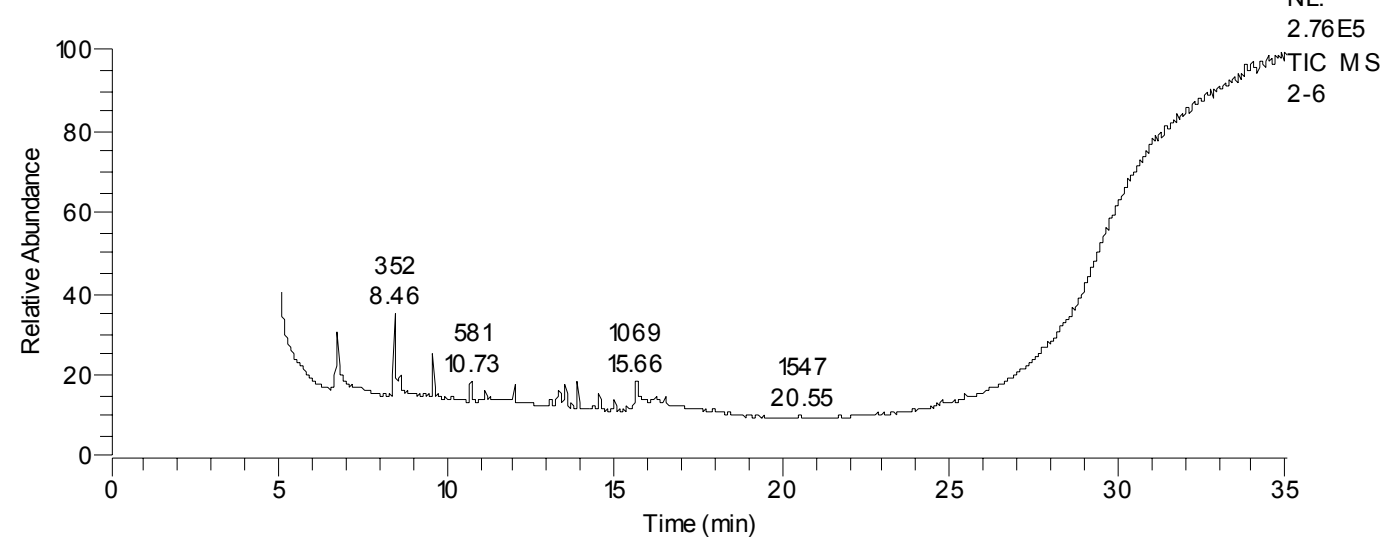

D: \Xcalibur $\backslash$ Data $\backslash$ GemmaH $\backslash$ peppers $100703 \backslash$

10/07/03 20:54:23

29.97

27

2.00

3038

35.00

550.00

D: XXcalibur $\backslash$ methods $\backslash$ pepper_PTV.meth

D: $\mid$ Xcalibur $\backslash$ methods $\backslash$ qualitativeID
$76 \mathrm{E} 5$

\begin{tabular}{|c|c|c|}
\hline RT & Peak Area & Area $\%$ \\
\hline 6.73 & 302004 & 18.78 \\
\hline 7.22 & 72522 & 4.51 \\
\hline 8.46 & 298467 & 18.56 \\
\hline 9.32 & 1888 & 0.12 \\
\hline 9.58 & 75871 & 4.72 \\
\hline 10.19 & 1406 & 0.09 \\
\hline 10.73 & 49595 & 3.08 \\
\hline 11.16 & 36887 & 2.29 \\
\hline 11.53 & 19393 & 1.21 \\
\hline 11.75 & 19524 & 1.21 \\
\hline 12.03 & 36871 & 2.29 \\
\hline 12.29 & 1643 & 0.10 \\
\hline 13.10 & 25625 & 1.59 \\
\hline 13.35 & 91997 & 5.72 \\
\hline $\begin{array}{l}13.53 \\
\end{array}$ & 78974 & 4.91 \\
\hline 13.74 & 47753 & 0.30 \\
\hline 13.91 & 46985 & 2.92 \\
\hline 14.39 & 9582 & 0.60 \\
\hline 14.56 & 25891 & 1.61 \\
\hline 15.00 & 29041 & 1.81 \\
\hline 15.66 & 214740 & 13.36 \\
\hline
\end{tabular}




\begin{tabular}{|l|l|l|}
\hline 16.25 & 106713 & 6.64 \\
\hline 16.51 & 30976 & 1.93 \\
\hline 17.95 & 1943 & 0.12 \\
\hline 19.30 & 2882 & 0.18 \\
\hline 20.55 & 1511 & 0.09 \\
\hline 21.74 & 1916 & 0.12 \\
\hline 22.09 & 1702 & 0.11 \\
\hline 24.77 & 5956 & 0.37 \\
\hline 25.45 & 5103 & 0.32 \\
\hline 27.77 & 5556 & 0.35 \\
\hline
\end{tabular}

\begin{tabular}{|c|c|c|c|c|c|c|}
\hline $\mathrm{T}$ & Name & I & rob. & $\begin{array}{l}\text { F } \\
\text { ormula }\end{array}$ & $\mathrm{W}$ & $\begin{array}{ll} & \mathrm{C} \\
\text { as \# } & \end{array}$ \\
\hline 5.45 & Benzo[k]fluoranthene & 74 & 6.53 & $20 \mathrm{H} 12$ & 52 & $\begin{array}{ll} & 2 \\
07-08-9 & \end{array}$ \\
\hline 5.45 & Perylene & 51 & 0.64 & $20 \mathrm{H} 12$ & 52 & $98-55-0$ \\
\hline 5.45 & Benzo[j]fluoranthene & 27 & .91 & $20 \mathrm{H} 12$ & 52 & $05-82-3$ \\
\hline 5.45 & Benz[e]acephenanthrylene & 24 & .11 & $20 \mathrm{H} 12$ & 52 & 2 \\
\hline 5.45 & Benzo[e]pyrene & 21 & .40 & $20 \mathrm{H} 12$ & 52 & $\begin{array}{ll} & 1 \\
92-97-2 & \end{array}$ \\
\hline
\end{tabular}


Data File: $\quad 2-13$

Curr Data Path:

Acquisition Date:

Run Time (min):

Vial:

Inj Vol $(\mu \mathrm{L})$ :

Scans:

Low Mass (m/z):

High Mass ( $\mathrm{m} / \mathrm{z})$ :

Inst Method:

Proc Method:

RT: $0.00-35.02$ SM : 7G

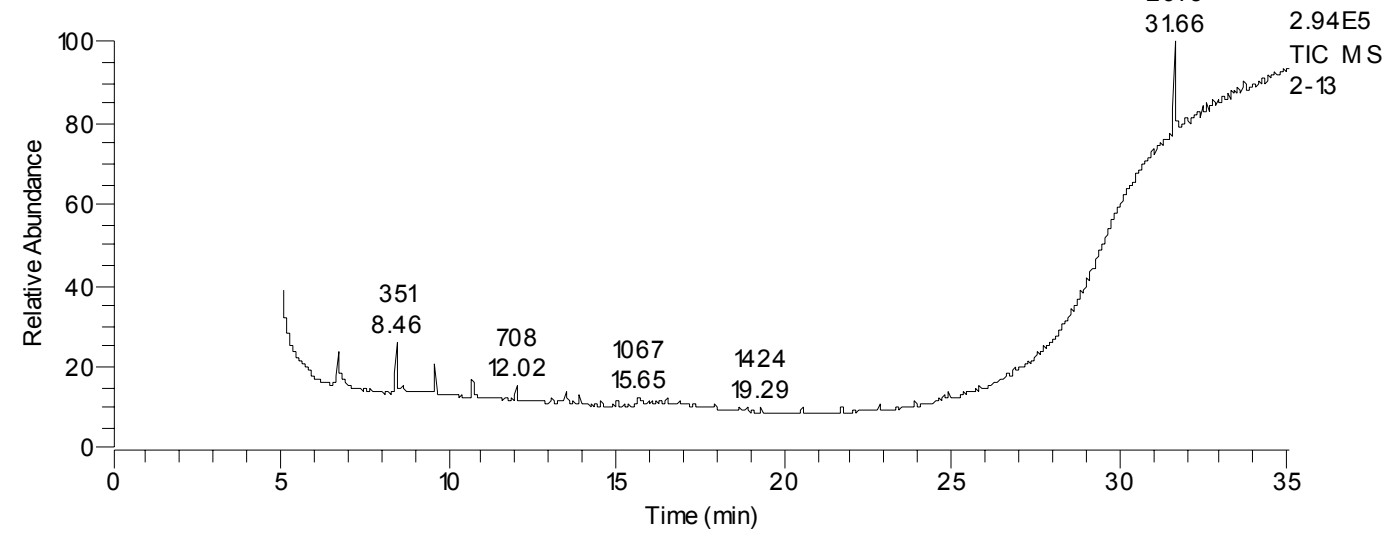

D: XXcalibur $\backslash$ Data $\backslash$ GemmaH $\backslash$ peppers $100703 \backslash$

10/07/03 21:46:05

29.98

28

2.00

3044

35.00

550.00

D:|Xcalibur|methods|pepper_PTV.meth

D: $\mid$ Xcalibur $\backslash$ methods $\backslash$ qualitativeID

\begin{tabular}{|c|c|c|}
\hline RT & Peak Area & Area \% \\
\hline 5.78 & 339 & 0.04 \\
\hline 6.73 & 161692 & 18.89 \\
\hline 7.33 & 1449 & 0.17 \\
\hline 7.67 & 2495 & 0.29 \\
\hline 8.46 & 151082 & 17.65 \\
\hline 9.30 & 5226 & 0.61 \\
\hline 9.58 & 53555 & 6.25 \\
\hline 10.73 & 33938 & 3.96 \\
\hline 12.02 & 23054 & 2.69 \\
\hline 13.07 & 11387 & 1.33 \\
\hline 13.51 & 50208 & 5.86 \\
\hline 13.73 & 2857 & 0.33 \\
\hline 13.90 & 15376 & 1.80 \\
\hline 14.38 & 1884 & 0.22 \\
\hline 14.56 & 3887 & 0.45 \\
\hline 15.02 & 16343 & 1.91 \\
\hline 15.66 & 65229 & 7.62 \\
\hline 16.09 & 29838 & 3.48 \\
\hline 16.28 & 31230 & 3.65 \\
\hline 16.52 & 55859 & 6.52 \\
\hline 16.89 & 38573 & 4.51 \\
\hline
\end{tabular}




\begin{tabular}{|l|l|l|}
\hline 17.33 & 7072 & 0.83 \\
\hline 17.96 & 5288 & 0.62 \\
\hline 18.70 & 9196 & 1.07 \\
\hline 18.90 & 2864 & 0.33 \\
\hline 19.30 & 5307 & 0.62 \\
\hline 20.54 & 7509 & 0.88 \\
\hline 21.74 & 6652 & 0.78 \\
\hline 22.86 & 7535 & 0.88 \\
\hline 23.92 & 9414 & 1.10 \\
\hline 24.90 & 8594 & 1.00 \\
\hline 25.44 & 4347 & 0.51 \\
\hline 25.83 & 5192 & 0.61 \\
\hline 26.26 & 1055 & 0.12 \\
\hline 26.70 & 3054 & 0.36 \\
\hline 26.89 & 6191 & 0.72 \\
\hline 27.53 & 5061 & 0.59 \\
\hline 27.77 & 6359 & 0.74 \\
\hline
\end{tabular}

\begin{tabular}{|c|c|c|c|c|c|c|}
\hline $\mathrm{T}$ & Name & I & rob. & $\begin{array}{l}\text { For } \\
\text { mula }\end{array}$ & W & Cas \\
\hline 6.89 & $\begin{array}{l}\text { Hexadecanoic acid, } \\
\text { 1a,2,5,5a,6,9,10,10a-octahydro-5,5a-dihydroxy-4- } \\
\text { (hydroxymethyl)-1,1,7,9-tetramethyl-11-oxo-1H- } \\
\text { 2,8a- } \\
\text { methanocyclopenta[a]cyclopropa[e]cyclodecen-6- } \\
\text { yl ester, [1aR-(1aà,2à,5á,5aá,6á,8aà,9à,10aà)]- }\end{array}$ & 74 & 0.05 & $\begin{array}{ll} & \mathrm{C} 36 \\
\mathrm{H} 58 \mathrm{O} 6 & \end{array}$ & 86 & $57-26-3$ \\
\hline 6.89 & $\begin{array}{l}\text { 9,10-Secocholesta-5,7,10(19)-triene- } \\
\text { 3,24,25-triol, (3á,5Z,7E)- }\end{array}$ & 41 & .25 & $\mathrm{H} 44 \mathrm{O} 3$ & 16 & $13-87-4$ \\
\hline 6.89 & 4a-Phorbol 12,13-didecanoate & 36 & .23 & H64O8 & 72 & NA \\
\hline 6.89 & $\begin{array}{l}\text { Hexadecanoic acid, 1-(hydroxymethyl)- } \\
\text { 1,2-ethanediyl ester }\end{array}$ & 32 & .57 & $\mathrm{H} 68 \mathrm{O} 5$ & 68 & $35-3$ \\
\hline 6.89 & $\begin{array}{l}\text { Octadecanoic acid, 2-hydroxy-1,3- } \\
\text { propanediyl ester }\end{array}$ & 32 & .57 & $\mathrm{H} 76 \mathrm{O} 5$ & 24 & $40-5$ \\
\hline
\end{tabular}


Data File:

Curr Data Path:

Acquisition Date:

Run Time (min):

Vial:

Inj Vol $(\mu \mathrm{L})$ :

Scans:

Low Mass $(\mathrm{m} / \mathrm{z})$ :

High Mass ( $\mathrm{m} / \mathrm{z})$ :

Inst Method:

Proc Method:

RT: $0.00-35.00$ SM : 7G

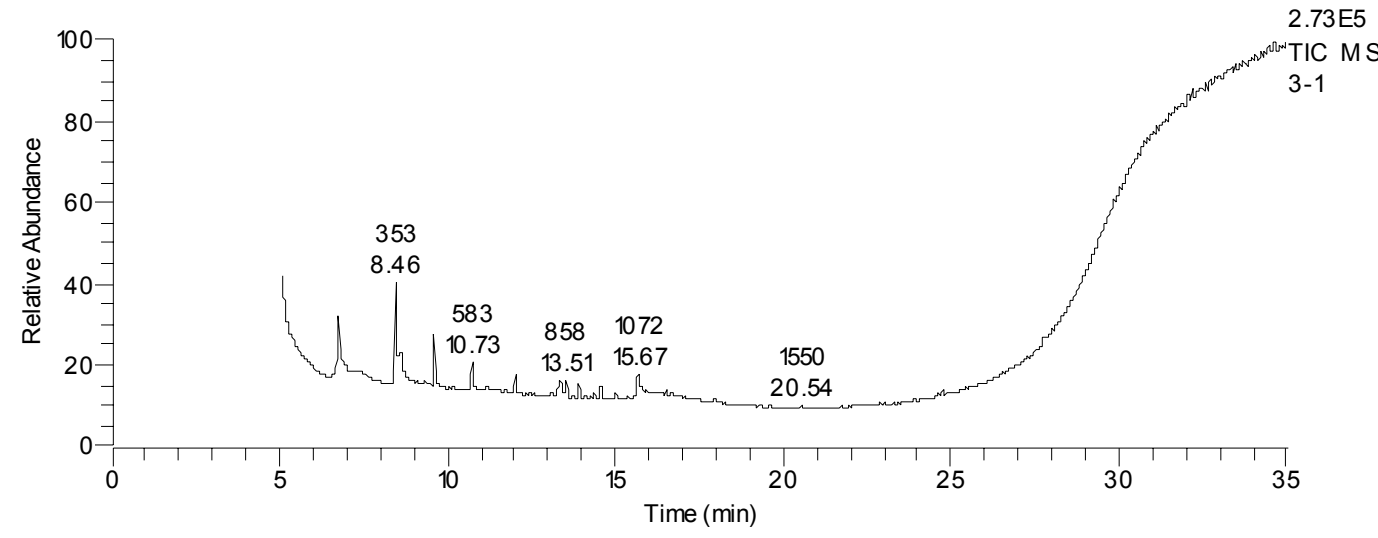

D:|Xcalibur|Data $\backslash G e m m a H \backslash p e p p e r s 100703 \backslash$

10/07/03 22:39:02

29.96

29

2.00

3040

35.00

550.00

D:|Xcalibur $\backslash$ methods $\mid$ pepper_PTV.meth

D: $|X c a l i b u r| m e t h o d s \backslash q u a l i t a t i v e I D$
$73 E 5$

\begin{tabular}{|c|c|c|}
\hline RT & Peak Area & Area \% \\
\hline 5.09 & 5429 & 0.32 \\
\hline 6.74 & 327311 & 19.27 \\
\hline 7.14 & 46885 & 2.76 \\
\hline 7.43 & 87232 & 5.14 \\
\hline 8.47 & 475319 & 27.99 \\
\hline 9.31 & 3469 & 0.20 \\
\hline 9.59 & 103286 & 6.08 \\
\hline 10.19 & 2326 & 0.14 \\
\hline 10.73 & 69963 & 4.12 \\
\hline 11.00 & 1242 & 0.07 \\
\hline 11.17 & 19646 & 1.16 \\
\hline 11.76 & 4156 & 0.24 \\
\hline 12.02 & 27609 & 1.63 \\
\hline 13.11 & 15077 & 0.89 \\
\hline 13.35 & 82022 & 4.83 \\
\hline 13.53 & 57075 & 3.36 \\
\hline 13.91 & 29026 & 1.71 \\
\hline 14.11 & 1686 & 0.10 \\
\hline 14.39 & 8320 & 0.49 \\
\hline 14.56 & 18951 & 1.12 \\
\hline 15.00 & 21167 & 1.25 \\
\hline
\end{tabular}




\begin{tabular}{|l|l|l|}
\hline 15.36 & 1450 & 0.09 \\
\hline 15.67 & 186522 & 10.98 \\
\hline 16.18 & 57070 & 3.36 \\
\hline 16.52 & 18945 & 1.12 \\
\hline 17.95 & 442 & 0.03 \\
\hline 19.30 & 1672 & 0.10 \\
\hline 20.54 & 1802 & 0.11 \\
\hline 21.74 & 1028 & 0.06 \\
\hline 22.09 & 291 & 0.02 \\
\hline 22.87 & 1774 & 0.10 \\
\hline 23.91 & 272 & 0.02 \\
\hline 24.77 & 8767 & 0.52 \\
\hline 25.45 & 3440 & 0.20 \\
\hline 27.53 & 2239 & 0.13 \\
\hline 27.77 & 5407 & 0.32 \\
\hline
\end{tabular}

\begin{tabular}{|c|c|c|c|c|c|c|}
\hline $\mathrm{T}$ & Name & I & rob. & Formula & W & Cas \\
\hline 4.39 & $\begin{array}{l}\text { Acetic acid, 3-acetoxy-5-pentyl-2-(4,6,6- } \\
\text { trimethylbicyclo[3.1.1]hept-3-en-2-yl)phenyl ester }\end{array}$ & 02 & .80 & $\mathrm{C} 25 \mathrm{H} 34$ & 98 & NA \\
\hline 4.39 & $\begin{array}{l}\text { 2á,4a-Epoxymethylphenanthrene-7- } \\
\text { methanol, } \quad \text { 1,1-dimethyl-2-methoxy-8-(1,3-dithiin-2- } \\
\text { ylidene)methyl-1,2,3,4,4a,4b,5,6,7,8,8a,9- } \\
\text { dodecahydro-, acetate }\end{array}$ & 97 & .48 & C27H38 & 90 & NA \\
\hline 4.39 & $\begin{array}{l}\text { 4H- } \\
\text { Cyclopropa[5',6']benz[1',2':7,8]azuleno[5,6-b]oxiren- } \\
\text { 4-one, 8,8a-bis(acetyloxy)-2a-[(acetyloxy)methyl]- } \\
\text { 1,1a,1b,1c,2a,3,3a,6a,6b,7,8,8a-dodecahydro-6b- } \\
\text { hydroxy-3a-methoxy-1,1,5,7-tetramethyl-, } \\
\text { (1aà,1bá,1cà,2aà,3aá,6aà,6bà,7à,8á,8aà)]- }\end{array}$ & 97 & .48 & C27H36 & 20 & 07-01-8 \\
\hline 4.39 & $\begin{array}{l}\text { 2,4,6(1H,3H,5H)-Pyrimidinetrione, } \\
\text { ethyl-1-methyl-5-[1-methyl-3- } \\
\text { [(trimethylsilyl)oxy]butyl]-3-(trimethylsilyl)- }\end{array}$ & 97 & .48 & $\mathrm{~N} 2 \mathrm{O} 4 \mathrm{Si} 2$ & 00 & $97-42-9$ \\
\hline 4.39 & $\begin{array}{l}\text { 9-Desoxy-9x-chloroingol } 3,7,8,12- \\
\text { tetraacetate }\end{array}$ & 96 & .26 & C28H39 & 54 & NA \\
\hline
\end{tabular}

\begin{tabular}{|c|c|c|c|c|c|c|}
\hline $\mathrm{T}$ & Name & I & rob. & mula & $\mathrm{W}$ & Cas \\
\hline 2.09 & Chrysene-d12 & 39 & 4.65 & D12 & 40 & $\begin{array}{ll} & 171 \\
9-03-5 & \end{array}$ \\
\hline 2.09 & $\begin{array}{l}\text { 1',1'-Dicarboethoxy-1á,2á-dihydro-3'H- } \\
\text { cycloprop[1,2]cholesta-1,4,6-trien-3-one }\end{array}$ & 84 & .78 & $\begin{array}{ll}\mathrm{C} 34 \\
\mathrm{H} 50 \mathrm{O} 5\end{array}$ & 38 & $57-74-8$ \\
\hline 2.09 & Ferrocene, 1-ethenyl-1'-ethyl- & 78 & .75 & $\mathrm{H} 16 \mathrm{Fe}$ & 40 & $35-62-6$ \\
\hline 2.09 & Ferrocene, 1,1'-(1,4-butanediyl)- & 70 & .80 & $\mathrm{H} 16 \mathrm{Fe}$ & 40 & $39-65-5$ \\
\hline 2.09 & $\begin{array}{l}\text { 12,13-Di-O-acetyl-20-desoxytigla- } \\
(1,6(20), 7) \text {-trien-3-one }\end{array}$ & 69 & .69 & $\begin{array}{ll}\mathrm{C} 24 \\
\mathrm{H} 30 \mathrm{O} 7\end{array}$ & 30 & NA \\
\hline
\end{tabular}



Data File: 3-6

Curr Data Path:

Acquisition Date:

Run Time (min):

Vial:

Inj Vol $(\mu \mathrm{L})$ :

Scans:

Low Mass $(\mathrm{m} / \mathrm{z})$ :

High Mass ( $\mathrm{m} / \mathrm{z})$ :

Inst Method:

Proc Method:

RT: $0.00-35.01$ SM : $7 G$

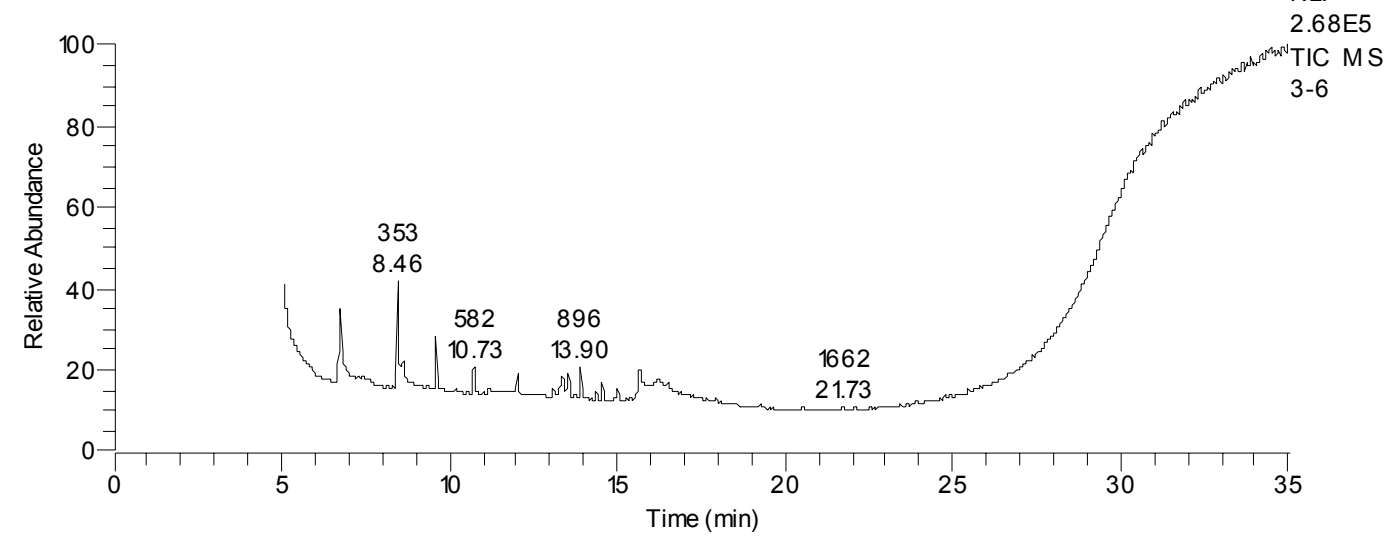

D:|Xcalibur|Data $\backslash G e m m a H \backslash p e p p e r s 100703 \backslash$

10/07/03 23:30:53

29.97

30

2.00

3034

35.00

550.00

D:|Xcalibur $\backslash$ methods $\mid$ pepper_PTV.meth

D: $|X c a l i b u r| m e t h o d s \backslash q u a l i t a t i v e I D$
E 5

\begin{tabular}{|c|c|c|}
\hline RT & Peak Area & Area $\%$ \\
\hline 6.73 & 365979 & 17.85 \\
\hline 7.12 & 80723 & 3.94 \\
\hline 7.43 & 56404 & 2.75 \\
\hline 8.46 & 401758 & 19.60 \\
\hline 9.31 & 2295 & 0.11 \\
\hline 9.59 & 99874 & 4.87 \\
\hline 10.19 & 5559 & 0.27 \\
\hline 10.73 & 61608 & 3.01 \\
\hline 11.17 & 21609 & 1.05 \\
\hline 11.49 & 5529 & 0.27 \\
\hline 11.74 & 8106 & 0.40 \\
\hline 12.03 & 29582 & 1.44 \\
\hline 13.11 & 23917 & 1.17 \\
\hline 13.36 & 112932 & 5.51 \\
\hline 13.53 & 98725 & 4.82 \\
\hline 13.90 & 54014 & 2.63 \\
\hline 14.11 & 1256 & 0.06 \\
\hline 14.38 & 19011 & 0.93 \\
\hline 14.56 & 31123 & 1.52 \\
\hline 15.01 & 38668 & 1.89 \\
\hline 15.67 & 197585 & 9.64 \\
\hline
\end{tabular}




\begin{tabular}{|l|l|l|}
\hline 15.96 & 56096 & 2.74 \\
\hline 16.24 & 258318 & 12.60 \\
\hline 17.95 & 1123 & 0.05 \\
\hline 19.29 & 1539 & 0.08 \\
\hline 21.73 & 2865 & 0.14 \\
\hline 24.78 & 4820 & 0.24 \\
\hline 25.46 & 3958 & 0.19 \\
\hline 26.71 & 2965 & 0.14 \\
\hline 27.76 & 2224 & 0.11 \\
\hline
\end{tabular}

\begin{tabular}{|c|c|c|c|c|c|c|}
\hline $\mathrm{T}$ & Name & I & rob. & Formula & $\mathrm{W}$ & Cas \\
\hline 4.38 & $\begin{array}{l}\text { Acetic acid, 3-acetoxy-5-pentyl-2- } \\
(4,6,6 \text {-trimethylbicyclo[3.1.1]hept-3-en-2- } \\
\text { yl)phenyl ester }\end{array}$ & 46 & 9.80 & $\mathrm{C} 25 \mathrm{H} 34$ & 98 & NA \\
\hline 4.38 & 3-Methoxydizepam & 42 & 6.73 & $\mathrm{ClN} 2 \mathrm{O} 2$ & 14 & $\begin{array}{ll} & 171 \\
91-70-7 & \end{array}$ \\
\hline 4.38 & $\begin{array}{l}\text { Pregnan-11-one, 17-hydroxy-3,20- } \\
\text { bis[(trimethylsilyl)oxy]-, (3à,5á,20S)- }\end{array}$ & 04 & .00 & C27H50 & 94 & $66-36-0$ \\
\hline 4.38 & $\begin{array}{c}\text { 1-Pentanol, } \\
\text { [2(diphenylhydroxymethyl)phenyl]- }\end{array}$ & 02 & .69 & $\mathrm{C} 24 \mathrm{H} 26$ & 46 & NA \\
\hline 4.38 & Cholan-6-ol-3-one-24-acid, ethyl ester & 96 & .90 & $\mathrm{C} 26 \mathrm{H} 42$ & 18 & NA \\
\hline
\end{tabular}


Data File:

Curr Data Path:

Acquisition Date:

Run Time (min):

Vial:

Inj Vol $(\mu \mathrm{L})$ :

Scans:

Low Mass $(\mathrm{m} / \mathrm{z})$ :

High Mass ( $\mathrm{m} / \mathrm{z})$ :

Inst Method:

Proc Method:
3-13

D:|Xcalibur|Data $\backslash$ GemmaH $\backslash$ peppers 100703\

10/08/03 01:13:21

29.99

51

2.00

3035

35.00

550.00

D:|Xcalibur|methods|pepper_PTV.meth

D: $\backslash$ Xcalibur $\backslash$ methods $\backslash$ qualitativeID

RT: $0.00-35.04$ SM: $7 G$

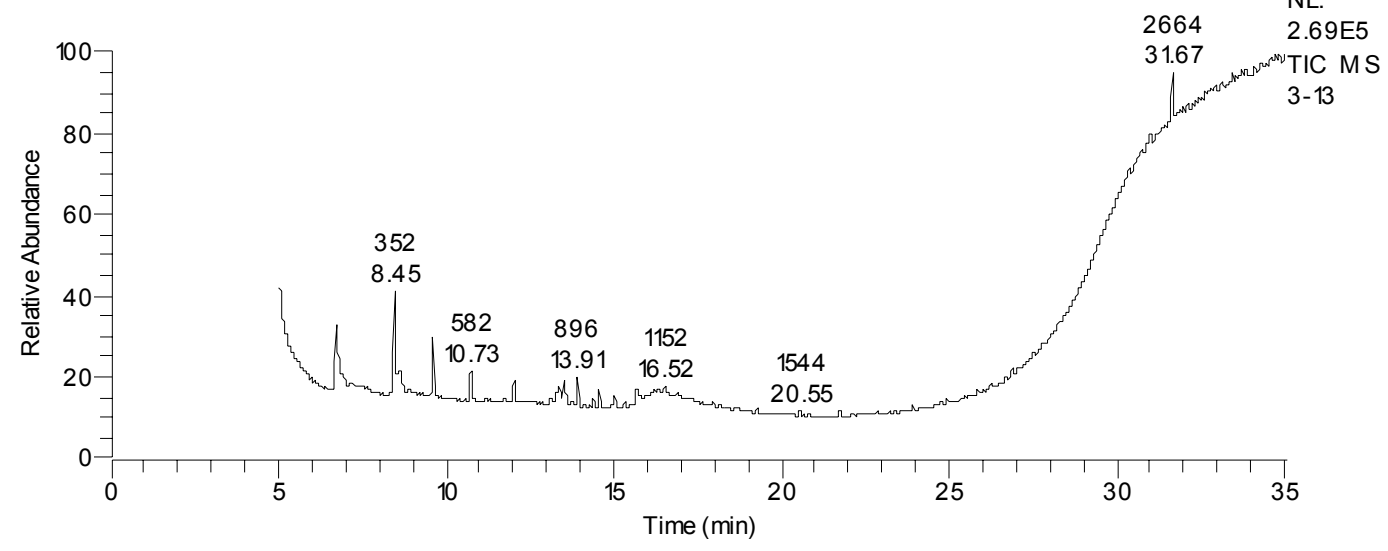

\begin{tabular}{|c|c|c|}
\hline RT & Peak Area & Area \% \\
\hline 6.74 & 342528 & 16.14 \\
\hline 7.18 & 99528 & 4.69 \\
\hline 8.46 & 386301 & 18.21 \\
\hline 9.59 & 105172 & 4.96 \\
\hline 10.20 & 1683 & 0.08 \\
\hline 10.72 & 64953 & 3.06 \\
\hline 11.18 & 2884 & 0.14 \\
\hline 11.76 & 4946 & 0.23 \\
\hline 12.02 & 33491 & 1.58 \\
\hline 13.11 & 16751 & 0.79 \\
\hline 13.36 & 96445 & 4.55 \\
\hline 13.53 & 89238 & 4.21 \\
\hline 13.74 & 3019 & 0.14 \\
\hline 13.91 & 49590 & 2.34 \\
\hline 14.38 & 14625 & 0.69 \\
\hline 14.57 & 27384 & 1.29 \\
\hline 15.01 & 35461 & 1.67 \\
\hline 15.69 & 82756 & 3.90 \\
\hline 16.33 & 244312 & 11.52 \\
\hline 16.52 & 175138 & 8.25 \\
\hline 16.89 & 167100 & 7.88 \\
\hline
\end{tabular}




\begin{tabular}{|l|l|l|}
\hline 17.96 & 5201 & 0.25 \\
\hline 18.67 & 3492 & 0.16 \\
\hline 19.29 & 6001 & 0.28 \\
\hline 20.55 & 5926 & 0.28 \\
\hline 21.74 & 4996 & 0.24 \\
\hline 22.86 & 4522 & 0.21 \\
\hline 23.91 & 5252 & 0.25 \\
\hline 24.77 & 4297 & 0.20 \\
\hline 24.90 & 4239 & 0.20 \\
\hline 25.45 & 2037 & 0.10 \\
\hline 25.83 & 3479 & 0.16 \\
\hline 26.24 & 4266 & 0.20 \\
\hline 26.69 & 2261 & 0.11 \\
\hline 26.89 & 10955 & 0.52 \\
\hline 27.05 & 4491 & 0.21 \\
\hline 27.52 & 5228 & 0.25 \\
\hline 27.78 & 1684 & 0.08 \\
\hline
\end{tabular}

\begin{tabular}{|c|c|c|c|c|c|c|c|}
\hline $\mathrm{T}$ & Name & I & rob. & $\begin{array}{l}\text { Formul } \\
\text { a }\end{array}$ & W & $\#$ & Cas \\
\hline 1.76 & $\begin{array}{l}\text { (5á)Pregnane-3,20á-diol, 14à,18à-[4- } \\
\text { methyl-3-oxo-(1-oxa-4-azabutane-1,4-diyl)]-, } \\
\text { diacetate }\end{array}$ & 36 & 2.97 & $\mathrm{C} 28 \mathrm{H} 4$ & 89 & & NA \\
\hline 1.76 & $\begin{array}{l}\text { 17á-Acetoxy-1',1'-dicarboethoxy-1á,2á- } \\
\text { dihydro-17à-methyl-3'H-cycloprop[1,2]-5à- } \\
\text { androst-1-en-3-one }\end{array}$ & 26 & .15 & $\mathrm{C} 29 \mathrm{H} 4$ & 02 & $97-22-9$ & 800 \\
\hline 1.76 & $\begin{array}{l}\text { Pregnane-15,20-dione, } \\
\text { tris(acetyloxy)-, (3á,5à,12á,14á)- }\end{array}$ & 22 & .73 & $\mathrm{C} 27 \mathrm{H} 3$ & 90 & $93-82-8$ & 554 \\
\hline 1.76 & $\begin{array}{l}\text { 2á,4a-Epoxymethylphenanthrene-7- } \\
\text { methanol, 1,1-dimethyl-2-methoxy-8-(1,3-dithiin- } \\
\text { 2-ylidene)methyl-1,2,3,4,4a,4b,5,6,7,8,8a,9- } \\
\text { dodecahydro-, acetate }\end{array}$ & 16 & .08 & $8 \mathrm{O} 4 \mathrm{~S} 2$ & 90 & & NA \\
\hline 1.76 & $\begin{array}{l}\text { 5H-Cyclopropa[3,4]benz[1,2-e]azulen- } \\
\text { 5-one, } \\
\text { 3,[(acetyloxy)methyl]- } \\
\text { 1,1a,1b,2,3a-tetrakis(acetyloxy)- } \\
\text { dihydroxy-1,1,6,8-tetramethyl-, } \\
\text { (1aà,1bá,2à,3á,4aá,7aà,7bà,8à,9á,9aà)]- }\end{array}$ & 15 & .84 & 0013 & 08 & $73-25-2$ & 775 \\
\hline $\mathrm{T}$ & Name & I & rob. & wla & W & & Cas \# \\
\hline 6.33 & 4'-Apo-á,.psi.-carotenoic acid & 88 & 9.26 & $\mathrm{H} 46 \mathrm{O} 2$ & 98 & $88-4$ & $2468-$ \\
\hline \multirow[t]{2}{*}{6.33} & $\begin{array}{l}\text { Ent-3a,10-dihydroxy-13-iodomethyl-16- } \\
\text { oxo-8,13-epi-17,20-dinorgibberell-1-en-7,19-dioic } \\
\text { acid,19,10-lactone,7-methyl ester }\end{array}$ & 52 & .23 & $\begin{array}{ll}\mathrm{C} 20 \\
\mathrm{H} 23 \mathrm{IO} 6\end{array}$ & 86 & $28-84-3$ & 1164 \\
\hline & D-Homo-24-nor-17-oxachola-20,22-diene- & & & $\mathrm{C} 28$ & & & 5565 \\
\hline
\end{tabular}




\begin{tabular}{|c|c|c|c|c|c|c|}
\hline 6.33 & $\begin{array}{l}\text { 3,16-dione, 7-(acetyloxy)-1,2:14,15:21,23-triepoxy- } \\
\text { 4,4,8-trimethyl-, (5à,7à,13à,14á,15á,17aà)- }\end{array}$ & 47 & .83 & $\mathrm{H} 34 \mathrm{O} 8$ & 98 & $8-66-7$ \\
\hline 6.33 & 9,19-Cyclolanostane-6,7-dione, 3-acetoxy- & 43 & .92 & H50O4 & 98 & NA \\
\hline 6.33 & $\begin{array}{l}\text { 10'-Apo-á,.psi.-carotenoic acid, } \\
\text { 5,6- } \\
\text { dihydro-5,6-dihydroxy-, methyl ester, }(5 \mathrm{R}, 6 \mathrm{R})-\end{array}$ & 37 & .87 & $\mathrm{H} 40 \mathrm{O} 4$ & 40 & $1256-$ \\
\hline
\end{tabular}

\begin{tabular}{|c|c|c|c|c|c|c|c|}
\hline $\mathrm{T}$ & Name & I & rob. & Formula & W & & Cas \# \\
\hline 6.89 & 4'-Apo-á,.psi.-carotenoic acid & 92 & 7.96 & $\mathrm{C} 35 \mathrm{H} 46$ & 98 & $88-4$ & $2468-$ \\
\hline 6.89 & $\begin{array}{l}\text { 3-Pyridinecarboxylic acid, 2,7,10- } \\
\text { tris(acetyloxy)-1,1a,2,3,4,6,7,10,11,11a-decahydro- } \\
\text { 1,1,3,6,9-pentamethyl-4-oxo-4a,7a-epoxy-5H- } \\
\text { cyclopenta[a]cyclopropa[f]cycloundecen-11-yl ester, } \\
\text { [1aR- } \\
\left(1 \mathrm{aR}^{*}, 2 \mathrm{R}^{*}, 3 \mathrm{~S}^{*}, 4 \mathrm{aR}^{*}, 6 \mathrm{~S}^{*}, 7 \mathrm{~S}^{*}, 7 \mathrm{aS}^{*}, 8 \mathrm{E}, 10 \mathrm{R}^{*}, 11 \mathrm{R}^{*}, 11\right. \\
\left.\left.\mathrm{aS}^{*}\right)\right]-\end{array}$ & 77 & 0.88 & $\mathrm{C} 32 \mathrm{H} 39$ & 97 & $6-00-4$ & 5190 \\
\hline 6.89 & $\begin{array}{c}\text { Octasiloxane, } \\
1,1,3,3,5,5,7,7,9,9,11,11,13,13,15,15 \text {-hexadecamethyl- }\end{array}$ & 64 & .03 & $\mathrm{C} 16 \mathrm{H} 50$ & 78 & $5-24-0$ & 1909 \\
\hline 6.89 & $\begin{array}{l}\text { D-Homo-24-nor-17-oxachola-20,22-diene- } \\
\text { 3,16-dione, } \quad \text { 7-(acetyloxy)-1,2:14,15:21,23-triepoxy- } \\
\text { 4,4,8-trimethyl-, (5à,7à,13à,14á,15á,17aà)- }\end{array}$ & 60 & .94 & $\mathrm{C} 28 \mathrm{H} 34$ & 98 & $8-66-7$ & 5565 \\
\hline 6.89 & $\begin{array}{l}\text { Ent-3a,10-dihydroxy-13-iodomethyl-16- } \\
\text { oxo-8,13-epi-17,20-dinorgibberell-1-en-7,19-dioic } \\
\text { acid,19,10-lactone,7-methyl ester }\end{array}$ & 60 & .94 & $\mathrm{C} 2 \mathrm{OH} 23$ & 86 & $28-84-3$ & 1164 \\
\hline
\end{tabular}


Data File:

Curr Data Path:

Acquisition Date:

Run Time (min):

Vial:

Inj Vol $(\mu \mathrm{L})$ :

Scans:

Low Mass (m/z):

High Mass ( $\mathrm{m} / \mathrm{z})$ :

Inst Method:

Proc Method:
4-1

D:|Xcalibur|Data $\backslash$ GemmaH $\backslash$ peppers 100703\

10/08/03 02:05:24

29.96

52

2.00

3032

35.00

550.00

D:|Xcalibur|methods|pepper_PTV.meth

D: $\backslash$ Xcalibur $\backslash$ methods $\backslash$ qualitativeID

RT: $0.00-35.01$ SM : $7 G$

$\mathrm{NL}$

2.69E5

TIC MS

4-1

\begin{tabular}{|c|c|c|}
\hline RT & Peak Area & Area \% \\
\hline 6.73 & 435435 & 16.53 \\
\hline 7.45 & 186247 & 7.07 \\
\hline 8.46 & 552347 & 20.97 \\
\hline 9.31 & 3272 & 0.12 \\
\hline 9.59 & 136652 & 5.19 \\
\hline 10.72 & 77951 & 2.96 \\
\hline 11.77 & 5271 & 0.20 \\
\hline 12.02 & 40707 & 1.55 \\
\hline 12.22 & 1791 & 0.07 \\
\hline 12.54 & 148 & 0.01 \\
\hline 13.12 & 16874 & 0.64 \\
\hline 13.36 & 113965 & 4.33 \\
\hline 13.53 & 100603 & 3.82 \\
\hline 13.91 & 53385 & 2.03 \\
\hline 14.38 & 15688 & 0.60 \\
\hline 14.57 & 30937 & 1.17 \\
\hline 15.01 & 37802 & 1.44 \\
\hline 15.36 & 7645 & 0.29 \\
\hline 15.70 & 85235 & 3.24 \\
\hline 16.33 & 296976 & 11.28 \\
\hline 16.51 & 394413 & 14.98 \\
\hline
\end{tabular}




\begin{tabular}{|l|l|l|}
\hline 17.95 & 7072 & 0.27 \\
\hline 19.29 & 1878 & 0.07 \\
\hline 20.54 & 2701 & 0.10 \\
\hline 21.73 & 2671 & 0.10 \\
\hline 22.86 & 836 & 0.03 \\
\hline 23.92 & 2656 & 0.10 \\
\hline 24.77 & 5380 & 0.20 \\
\hline 24.89 & 5090 & 0.19 \\
\hline 25.44 & 4095 & 0.16 \\
\hline 25.82 & 1961 & 0.07 \\
\hline 26.70 & 2271 & 0.09 \\
\hline 27.77 & 3466 & 0.13 \\
\hline
\end{tabular}

\begin{tabular}{|c|c|c|c|c|c|c|}
\hline $\mathrm{T}$ & Name & I & rob. & Formul & W & Cas \\
\hline 1.77 & $\begin{array}{l}\text { 2á,4a-Epoxymethylphenanthrene-7- } \\
\text { methanol, } \quad \text { 1,1-dimethyl-2-methoxy-8-(1,3-dithiin-2- } \\
\text { ylidene)methyl-1,2,3,4,4a,4b,5,6,7,8,8a,9- } \\
\text { dodecahydro-, acetate }\end{array}$ & 39 & 5.72 & $\mathrm{C} 27 \mathrm{H} 3$ & 90 & NA \\
\hline 1.77 & $\begin{array}{l}\text { Pregn-9(11)-en-3-one, 18,20-dihydroxy-, } \\
\text { cyclic 1,2-ethanediyl acetal, (5à,20R)- }\end{array}$ & 12 & .56 & $\mathrm{C} 23 \mathrm{H} 3$ & 76 & $66-63-7$ \\
\hline 1.77 & $\begin{array}{l}\text { D-Homo-24-nor-17-oxachola-20,22-dien- } \\
\text { 16-one, } \quad \text { 1,3,7-tris(acetyloxy)-14,15:21,23-diepoxy- } \\
\text { 4,4,8-trimethyl-, (1à,3à,5à,7à,13à,14á,15á,17aà)- }\end{array}$ & 12 & .56 & $2 \mathrm{O} 10$ & 86 & $4-38-1$ \\
\hline 1.77 & $\begin{array}{l}\text { 3'H-Cycloprop(1,2)cholesta-1,4,6-trien-3- } \\
\text { one, 1'-carboethoxy-1'-cyano-1á,2á-dihydro- }\end{array}$ & 06 & .94 & $5 \mathrm{NO} 3$ & 91 & $57-78-2$ \\
\hline 1.77 & $\begin{array}{l}\text { 1H-Cyclopropa[3,4]benz[1,2-e]azulene-3- } \\
\text { carboxaldehyde, } \\
\text { 1a,1b,4,4a,5,7a,7b,8,9,9a-decahydro-4a,7b-dihydroxy- } \\
\text { 1,1,6,8-tetramethyl-5,9-dioxo-, } \\
\text { (1aà,1bá,4aá,7aà,7bà,8à,9aà)]- }\end{array}$ & 00 & .67 & $\mathrm{C} 22 \mathrm{H} 2$ & 02 & $73-49-0$ \\
\hline
\end{tabular}

\begin{tabular}{|c|c|c|c|c|c|c|c|}
\hline $\mathrm{T}$ & Name & I & rob. & Formula & $\mathrm{W}$ & & Cas \# \\
\hline 5.70 & 4'-Apo-á,.psi.-carotenoic acid & 68 & 8.04 & C35H46 & 98 & $88-4$ & $2468-$ \\
\hline 5.70 & $\begin{array}{l}\text { Ent-3a,10-dihydroxy-13-iodomethyl-16- } \\
\text { oxo-8,13-epi-17,20-dinorgibberell-1-en-7,19-dioic } \\
\text { acid,19,10-lactone,7-methyl ester }\end{array}$ & 47 & .67 & $\mathrm{C} 20 \mathrm{H} 23$ & 86 & $28-84-3$ & 1164 \\
\hline 5.70 & $\begin{array}{l}\text { D-Homo-24-nor-17-oxachola-20,22-diene- } \\
\text { 3,16-dione, } \quad \text { 7-(acetyloxy)-1,2:14,15:21,23-triepoxy- } \\
\text { 4,4,8-trimethyl-, (5à,7à,13à,14á,15á,17aà)- }\end{array}$ & 45 & .08 & C28H34 & 98 & $8-66-7$ & 5565 \\
\hline 5.70 & $\begin{array}{l}\text { 3-Pyridinecarboxylic acid, 2,7,10- } \\
\text { tris(acetyloxy)-1,1a,2,3,4,6,7,10,11,11a-decahydro- } \\
\text { 1,1,3,6,9-pentamethyl-4-oxo-4a,7a-epoxy-5H- } \\
\text { cyclopenta[a]cyclopropa[f]cycloundecen-11-yl ester, } \\
\text { [1aR- }\end{array}$ & 45 & .08 & C32H39 & 97 & $6-00-4$ & 5190 \\
\hline
\end{tabular}




\begin{tabular}{|c|c|c|c|c|c|c|}
\hline & $\begin{array}{l}\left(1 \mathrm{aR} *, 2 \mathrm{R}^{*}, 3 \mathrm{~S}^{*}, 4 \mathrm{aR} *, 6 \mathrm{~S}^{*}, 7 \mathrm{~S}^{*}, 7 \mathrm{aS} *, 8 \mathrm{E}, 10 \mathrm{R}^{*}, 11 \mathrm{R}^{*}, 11\right. \\
\left.\left.\mathrm{aS}^{*}\right)\right]-\end{array}$ & & & & & \\
\hline 5.70 & 9,19-Cyclolanostane-6,7-dione, 3-acetoxy- & 37 & .28 & $\begin{array}{ll} & \mathrm{C} 32 \mathrm{H} 50 \\
\mathrm{O} 4 & \end{array}$ & 98 & NA \\
\hline
\end{tabular}

\begin{tabular}{|c|c|c|c|c|c|c|c|}
\hline $\mathrm{T}$ & Name & I & rob. & Formula & $\mathrm{W}$ & & Cas \# \\
\hline 6.33 & 4'-Apo-á,.psi.-carotenoic acid & 85 & 7.98 & C35H46 & 98 & $88-4$ & $2468-$ \\
\hline 6.33 & $\begin{array}{l}\text { Ent-3a,10-dihydroxy-13-iodomethyl-16- } \\
\text { oxo-8,13-epi-17,20-dinorgibberell-1-en-7,19-dioic } \\
\text { acid,19,10-lactone,7-methyl ester }\end{array}$ & 51 & .17 & $\mathrm{C} 2 \mathrm{OH} 23$ & 86 & $28-84-3$ & 1164 \\
\hline 6.33 & $\begin{array}{l}\text { D-Homo-24-nor-17-oxachola-20,22-diene- } \\
\text { 3,16-dione, } \quad \text { 7-(acetyloxy)-1,2:14,15:21,23-triepoxy- } \\
\text { 4,4,8-trimethyl-, (5à,7à,13à,14á,15á,17aà)- }\end{array}$ & 46 & .78 & $\mathrm{C} 28 \mathrm{H} 34$ & 98 & $8-66-7$ & 5565 \\
\hline 6.33 & $\begin{array}{l}\text { 3-Pyridinecarboxylic acid, 2,7,10- } \\
\text { tris(acetyloxy)-1,1a,2,3,4,6,7,10,11,11a-decahydro- } \\
\text { 1,1,3,6,9-pentamethyl-4-oxo-4a,7a-epoxy-5H- } \\
\text { cyclopenta[a]cyclopropa[f]cycloundecen-11-yl ester, } \\
\text { [1aR- } \\
\left(1 \mathrm{aR}^{*}, 2 \mathrm{R}^{*}, 3 \mathrm{~S}^{*}, 4 \mathrm{aR}^{*}, 6 \mathrm{~S}^{*}, 7 \mathrm{~S}^{*}, 7 \mathrm{aS} *, 8 \mathrm{E}, 10 \mathrm{R}^{*}, 11 \mathrm{R}^{*}, 11\right. \\
\left.\left.\mathrm{aS}^{*}\right)\right]-\end{array}$ & 45 & .55 & NO10 & 97 & $6-00-4$ & 5190 \\
\hline 6.33 & 9,19-Cyclolanostane-6,7-dione, 3-acetoxy- & 41 & .69 & $\mathrm{C} 32 \mathrm{H} 50$ & 98 & & NA \\
\hline
\end{tabular}


Data File: 4-6

Curr Data Path:

Acquisition Date:

Run Time (min):

Vial:

Inj Vol $(\mu \mathrm{L})$ :

Scans:

Low Mass $(\mathrm{m} / \mathrm{z})$ :

High Mass ( $\mathrm{m} / \mathrm{z})$ :

Inst Method:

Proc Method:

RT: $0.00-35.03$ SM : 7G

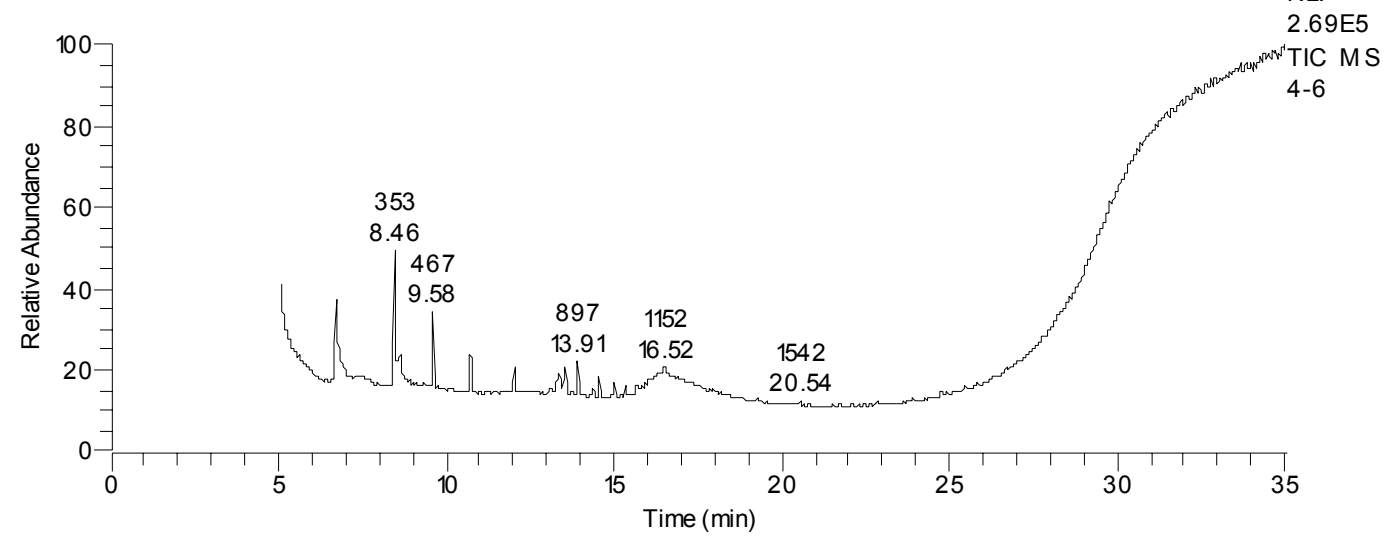

D:|Xcalibur|Data $\backslash$ GemmaH $\backslash$ peppers $100703 \backslash$

10/08/03 02:56:46

29.99

53

2.00

3031

35.00

550.00

D:|Xcalibur|methods|pepper_PTV.meth

D: $\mid$ Xcalibur $\backslash$ methods $\backslash$ qualitativeID
E5

\begin{tabular}{|c|c|c|}
\hline RT & Peak Area & Area \% \\
\hline 6.73 & 433819 & 17.98 \\
\hline 7.13 & 36185 & 1.50 \\
\hline 7.43 & 124320 & 5.15 \\
\hline 8.46 & 499933 & 20.73 \\
\hline 9.31 & 1537 & 0.06 \\
\hline 9.58 & 140021 & 5.80 \\
\hline 10.21 & 945 & 0.04 \\
\hline 10.73 & 83312 & 3.45 \\
\hline 11.76 & 1918 & 0.08 \\
\hline 12.02 & 38250 & 1.59 \\
\hline 12.29 & 2486 & 0.10 \\
\hline 12.55 & 844 & 0.04 \\
\hline 13.12 & 16806 & 0.70 \\
\hline 13.35 & 100623 & 4.17 \\
\hline 13.52 & 98451 & 4.08 \\
\hline 13.92 & 73567 & 3.05 \\
\hline 14.38 & 15120 & 0.63 \\
\hline 14.56 & 29370 & 1.22 \\
\hline 15.00 & 35845 & 1.49 \\
\hline 15.35 & 8660 & 0.36 \\
\hline 15.68 & 18117 & 0.75 \\
\hline
\end{tabular}




\begin{tabular}{|l|l|l|}
\hline 16.50 & 616282 & 25.55 \\
\hline 17.95 & 3818 & 0.16 \\
\hline 19.29 & 2878 & 0.12 \\
\hline 20.54 & 2755 & 0.11 \\
\hline 21.74 & 3502 & 0.15 \\
\hline 22.87 & 3107 & 0.13 \\
\hline 23.91 & 1873 & 0.08 \\
\hline 24.77 & 4247 & 0.18 \\
\hline 24.90 & 2984 & 0.12 \\
\hline 25.45 & 1294 & 0.05 \\
\hline 25.82 & 1234 & 0.05 \\
\hline 26.69 & 1503 & 0.06 \\
\hline 27.52 & 897 & 0.04 \\
\hline 27.77 & 5717 & 0.24 \\
\hline
\end{tabular}

\begin{tabular}{|c|c|c|c|c|c|c|}
\hline $\mathrm{T}$ & Name & I & rob. & Formula & W & Cas \\
\hline 3.35 & $\begin{array}{l}\text { 21H-Biline-8,12-dipropanoic acid, 3,17- } \\
\text { diethyl-1,2,3,4,5,19,23,24-octahydro-2,7,13,18- } \\
\text { tetramethyl-1,19-dioxo-, dimethyl ester, (2R,3R,4R)- }\end{array}$ & 48 & 6.00 & $\mathrm{C} 35 \mathrm{H} 46$ & 18 & $62-23-4$ \\
\hline 3.35 & $\begin{array}{l}\text { 21H-Biline-8,12-dipropanoic acid, 2,17- } \\
\text { diethyl-1,2,3,4,5,19,23,24-octahydro-3,7,13,18- } \\
\text { tetramethyl-1,19-dioxo-, dimethyl ester, (2R,3R,4R)- }\end{array}$ & 20 & 6.17 & $\mathrm{C} 35 \mathrm{H} 46$ & 18 & $89-77-3$ \\
\hline 3.35 & $\begin{array}{l}\text { 1'H-Cholest-2-eno[3,2-b]indole, 5'-chloro-, } \\
\text { (5à)- }\end{array}$ & 03 & .82 & C33H48 & 93 & $35-54-1$ \\
\hline 3.35 & $\begin{array}{c}\text { Silane, } \\
\text { [(dichlorostannylene)dimethylidyne]tetrakis[trimethyl- }\end{array}$ & 98 & .11 & $\mathrm{Cl} 2 \mathrm{Si} 4 \mathrm{Sn}$ & 08 & $89-73-5$ \\
\hline 3.35 & $\begin{array}{l}\text { 21H-Biline-8,12-dipropanoic acid, 2,18- } \\
\text { diethyl-1,4,5,19,23,24-hexahydro-3,7,13,17- } \\
\text { tetramethyl-1,19-dioxo-, dimethyl ester, (4R)- }\end{array}$ & 42 & .35 & $\mathrm{C} 35 \mathrm{H} 44$ & 16 & $89-75-1$ \\
\hline
\end{tabular}


Data File:

Curr Data Path:

Acquisition Date:

Run Time (min):

Vial:

Inj Vol $(\mu \mathrm{L})$ :

Scans:

Low Mass (m/z):

High Mass ( $\mathrm{m} / \mathrm{z})$ :

Inst Method:

Proc Method:
4-13

D:|Xcalibur|Data $\backslash G e m m a H \backslash p e p p e r s 100703 \backslash$

10/08/03 03:47:33

29.96

54

2.00

3033

35.00

550.00

D:|Xcalibur|methods|pepper_PTV.meth

D: IXcalibur $\backslash$ methods $\backslash q u a l i t a t i v e I D$

RT: $0.00-35.01$ SM : $7 G$

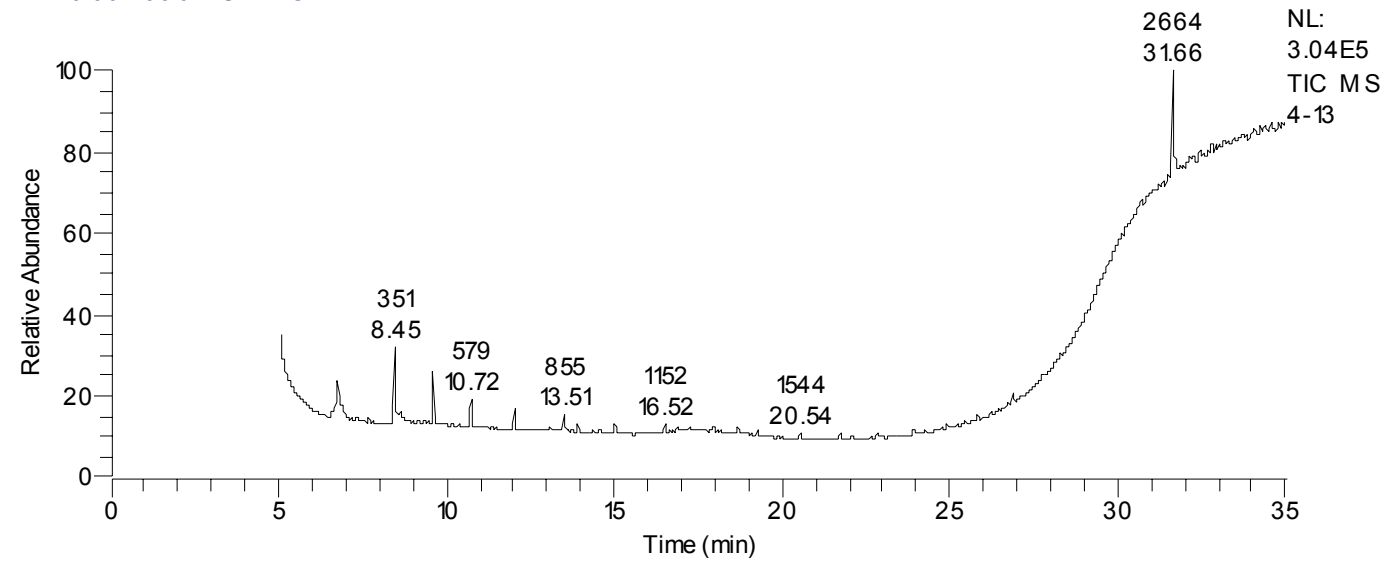

\begin{tabular}{|c|c|c|}
\hline RT & Peak Area & Area \% \\
\hline 6.74 & 247541 & 23.99 \\
\hline 7.70 & 2720 & 0.26 \\
\hline 8.46 & 269868 & 26.16 \\
\hline 9.32 & 2745 & 0.27 \\
\hline 9.58 & 105355 & 10.21 \\
\hline 10.72 & 49817 & 4.83 \\
\hline 12.02 & 32746 & 3.17 \\
\hline 13.07 & 6424 & 0.62 \\
\hline 13.51 & 47817 & 4.64 \\
\hline 13.73 & 2899 & 0.28 \\
\hline 13.90 & 14332 & 1.39 \\
\hline 14.56 & 2178 & 0.21 \\
\hline 15.02 & 20584 & 2.00 \\
\hline 15.36 & 1103 & 0.11 \\
\hline 16.52 & 10803 & 1.05 \\
\hline 16.90 & 11747 & 1.14 \\
\hline 17.26 & 26199 & 2.54 \\
\hline 17.45 & 35654 & 3.46 \\
\hline 17.95 & 22349 & 2.17 \\
\hline 18.17 & 2902 & 0.28 \\
\hline 18.68 & 24370 & 2.36 \\
\hline
\end{tabular}




\begin{tabular}{|l|l|l|}
\hline 18.90 & 2706 & 0.26 \\
\hline 19.29 & 8188 & 0.79 \\
\hline 20.54 & 8645 & 0.84 \\
\hline 21.74 & 8256 & 0.80 \\
\hline 22.86 & 8363 & 0.81 \\
\hline 23.91 & 6551 & 0.63 \\
\hline 24.90 & 6585 & 0.64 \\
\hline 25.44 & 1953 & 0.19 \\
\hline 25.83 & 5068 & 0.49 \\
\hline 26.25 & 5195 & 0.50 \\
\hline 26.71 & 4977 & 0.48 \\
\hline 26.89 & 18668 & 1.81 \\
\hline 27.51 & 2002 & 0.19 \\
\hline 27.77 & 4328 & 0.42 \\
\hline
\end{tabular}

\begin{tabular}{|c|c|c|c|c|c|c|}
\hline RT & Name & I & rob. & Formula & $\mathrm{W}$ & Cas \\
\hline 6.90 & $\begin{array}{l}\text { Pregnane-3,11,20,21-tetrol, cyclic 20,21- } \\
\text { (butyl boronate), (3à,5á,11á,20R)- }\end{array}$ & 57 & 0.98 & $\mathrm{C} 25 \mathrm{H} 43$ & 18 & $56-74-6$ \\
\hline 6.90 & $\begin{array}{l}\text { Spirost-8-en-11-one, } \\
\text { (3á,5à,14á,20á,22á,25R)- }\end{array}$ & 47 & .75 & $\mathrm{C} 27 \mathrm{H} 40$ & 28 & $72-54-1$ \\
\hline 6.90 & $\begin{array}{lll} & \text { Tetradecanoic acid, 12-methyl-, methyl } \\
\text { ester } & & \end{array}$ & 44 & .85 & $\mathrm{C} 16 \mathrm{H} 32$ & 56 & $9-66-8$ \\
\hline 6.90 & $\begin{array}{l}\text { 17-(1,5-Dimethylhexyl)-10,13-dimethyl-3- } \\
\text { styrylhexadecahydrocyclopenta[a]phenanthren-2-one }\end{array}$ & 43 & .58 & C35H52 & 88 & NA \\
\hline 6.90 & $\begin{array}{l}\text { 2,7-Diphenyl-1,6-dioxopyridazino[4,5- } \\
\text { 2',3']pyrrolo[4',5'-D]pyridazine }\end{array}$ & 40 & .82 & $\mathrm{C} 20 \mathrm{H} 13$ & 55 & $57-06-1$ \\
\hline $\mathrm{T}$ & Name & I & rob. & $\begin{array}{l}\text { Formu } \\
\text { la }\end{array}$ & $\mathrm{W}$ & Cas \\
\hline 8.68 & $\begin{array}{lll}9,12,15-O c t a d e c a t r i e n o i c & \text { acid, } & 2,3- \\
\text { dihydroxypropyl ester, }(\mathrm{Z}, \mathrm{Z}, \mathrm{Z})- & \end{array}$ & 14 & 0.59 & $36 \mathrm{O} 4$ & 52 & $65-99-1$ \\
\hline 8.68 & Cyclooctenone, dimer & 11 & .35 & $\mathrm{C} 16 \mathrm{H}$ & 48 & $\begin{array}{ll} & 612 \\
19-51-0 & \end{array}$ \\
\hline 8.68 & Pseudosolasodine diacetate & 05 & .35 & $\mathrm{C} 31 \mathrm{H}$ & 99 & NA \\
\hline 8.68 & $\begin{array}{l}\text { 9,12-Octadecadienoic acid, methyl ester, } \\
\text { (E,E)- }\end{array}$ & 98 & .63 & $34 \mathrm{O} 2$ & 94 & $6-97-4$ \\
\hline 8.68 & $\begin{array}{l}\text { Acetic acid, 17-acetoxy-3-hydroxyimino- } \\
\text { 4,4,13-trimethyl- } \\
\text { hexadecahydrocyclopenta[a]phenanthren-10-ylmethyl } \\
\text { ester }\end{array}$ & 90 & .20 & 39NO5 & 33 & NA \\
\hline $\mathrm{T}$ & Name & I & rob. & la & $\mathrm{W}$ & Cas \\
\hline 8.90 & $\begin{array}{l}\text { Spirosolan-3-ol, 28-acetyl-, acetate (ester), } \\
\text { (3á,5à,22á,25S)- }\end{array}$ & 11 & .11 & $49 \mathrm{NO} 4$ & 99 & $1-86-8$ \\
\hline & 1a,2,5,5a,6,9,10,10a- & & & $\mathrm{C} 24 \mathrm{H}$ & & 775 \\
\hline
\end{tabular}




\begin{tabular}{|c|c|c|c|c|c|c|}
\hline 8.90 & $\begin{array}{l}\text { octahydro-5a-hydroxy-4-(hydroxymethyl)-1,1,7,9- } \\
\text { tetramethyl-6,11-dioxo-1H-2,8a- } \\
\text { methanocyclopenta[a]cyclopropa[e]cyclodecen-5-yl } \\
\text { ester, [1aR-(1aà,2à,5á,5aá,8aà,9à,10aà)]- }\end{array}$ & 04 & .97 & $32 \mathrm{O} 6$ & 16 & 08-70-4 \\
\hline 8.90 & $\begin{array}{l}\text { (5á,13á) Androst-8-en-3-one, } \\
\text { diacetoxy-4,4-dimethyl- }\end{array}$ & 96 & .20 & $36 \mathrm{O}=\mathrm{C} 25 \mathrm{H}$ & 16 & $\mathrm{NA}$ \\
\hline 8.90 & $\begin{array}{l}\text { Hexadecanoic acid, 2-(hexadecyloxy)ethyl } \\
\text { ester }\end{array}$ & 91 & .19 & $\mathrm{C} 34 \mathrm{H}$ & 24 & $43-32-5$ \\
\hline 8.90 & $\begin{array}{l}\text { 6-(1,5-Dimethyl-hex-4-enyl)-1,6- } \\
\text { dihydroxy-1,8a-dimethyl-3-oxo- } \\
\text { 1,2,3,3a,5a,6,7,8,8a,9,10,10a- } \\
\text { dodecahydrodicyclopenta[a,E]cyclooctene }\end{array}$ & 91 & .19 & 3804 & 02 & NA \\
\hline
\end{tabular}

\begin{tabular}{|c|c|c|c|c|c|c|}
\hline $\mathrm{T}$ & Name & I & rob. & Formul & W & Cas \\
\hline 6.89 & $\begin{array}{llll} & \text { Stigmastan-3-ol, } & \text { 5-chloro-, } & \text { acetate, } \\
\text { (3á,5à)- } & & \end{array}$ & 36 & 1.19 & $\begin{array}{ll}\mathrm{C} 31 \mathrm{H} 5 \\
3 \mathrm{ClO} 2\end{array}$ & 92 & $24-19-1$ \\
\hline 6.89 & Stigmastan-3,5-dien & 23 & 3.69 & $\begin{array}{l}\mathrm{C} 29 \mathrm{H} 4 \\
8\end{array}$ & 96 & NA \\
\hline 6.89 & Stigmast-5-en-3-ol, oleate & 21 & 2.62 & $\begin{array}{ll}\mathrm{C} 47 \mathrm{H} 8 \\
2 \mathrm{O} 2\end{array}$ & 78 & NA \\
\hline 6.89 & á-Sitosterol acetate & 15 & .92 & $\mathrm{C} 31 \mathrm{H} 5$ & 56 & $05-9$ \\
\hline 6.89 & Sitosterol acetate & 02 & .41 & $\begin{array}{ll}\mathrm{O} 2 & \mathrm{C} 31 \mathrm{H} 5 \\
\end{array}$ & 56 & NA \\
\hline
\end{tabular}


Data File:

Curr Data Path:

Acquisition Date:

Run Time (min):

Vial:

Inj Vol $(\mu \mathrm{L})$ :

Scans:

Low Mass $(\mathrm{m} / \mathrm{z})$ :

High Mass ( $\mathrm{m} / \mathrm{z})$ :

Inst Method:

Proc Method:
$5-1$

D:|Xcalibur|Data $\backslash$ GemmaH $\backslash$ peppers 100703\

10/08/03 06:18:17

29.95

57

2.00

3037

35.00

550.00

D:|Xcalibur|methods|pepper_PTV.meth

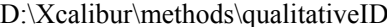

RT: $0.00-35.00$ SM : $7 G$

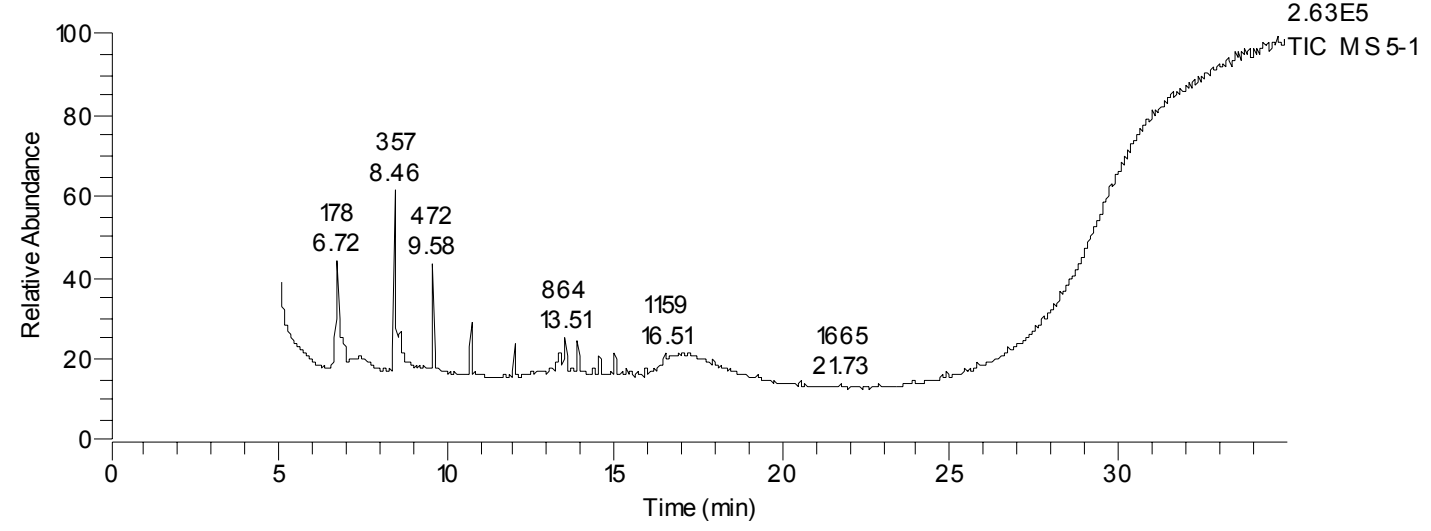

\begin{tabular}{|c|c|c|}
\hline RT & Peak Area & Area \% \\
\hline 6.73 & 570024 & 19.29 \\
\hline 7.18 & 56481 & 1.91 \\
\hline 7.39 & 138209 & 4.68 \\
\hline 8.47 & 652059 & 22.07 \\
\hline 9.58 & 192279 & 6.51 \\
\hline 10.73 & 102313 & 3.46 \\
\hline 11.11 & 1827 & 0.06 \\
\hline 12.02 & 43760 & 1.48 \\
\hline 13.36 & 118029 & 3.99 \\
\hline 13.52 & 126853 & 4.29 \\
\hline 13.91 & 83966 & 2.84 \\
\hline 14.11 & 6038 & 0.20 \\
\hline 14.38 & 15289 & 0.52 \\
\hline 14.56 & 29181 & 0.99 \\
\hline 15.01 & 52553 & 1.78 \\
\hline 15.36 & 21608 & 0.73 \\
\hline 15.52 & 5191 & 0.18 \\
\hline 15.69 & 2456 & 0.08 \\
\hline 15.95 & 7874 & 0.27 \\
\hline 16.51 & 77810 & 2.63 \\
\hline 17.00 & 289649 & 9.80 \\
\hline
\end{tabular}




\begin{tabular}{|l|l|l|}
\hline 17.25 & 281766 & 9.54 \\
\hline 17.95 & 35271 & 1.19 \\
\hline 19.29 & 3056 & 0.10 \\
\hline 20.54 & 4500 & 0.15 \\
\hline 21.73 & 3482 & 0.12 \\
\hline 22.86 & 3778 & 0.13 \\
\hline 23.92 & 4445 & 0.15 \\
\hline 24.90 & 7286 & 0.25 \\
\hline 25.44 & 2300 & 0.08 \\
\hline 25.83 & 4522 & 0.15 \\
\hline 26.69 & 4081 & 0.14 \\
\hline 27.52 & 2304 & 0.08 \\
\hline 27.77 & 4230 & 0.14 \\
\hline
\end{tabular}

\begin{tabular}{|c|c|c|c|c|c|c|}
\hline $\mathrm{T}$ & Name & I & rob. & Formula & W & Cas \\
\hline 4.56 & $\begin{array}{l}\text { 21H-Biline-8,12-dipropanoic acid, 3,17- } \\
\text { diethyl-1,2,3,4,5,19,23,24-octahydro-2,7,13,18- } \\
\text { tetramethyl-1,19-dioxo-, dimethyl ester, (2R,3R,4R)- }\end{array}$ & 89 & 3.16 & $\mathrm{C} 35 \mathrm{H} 46$ & 18 & $62-23-4$ \\
\hline 4.56 & $\begin{array}{l}\text { 1'H-Cholest-2-eno[3,2-b]indole, 5'-chloro-, } \\
\text { (5à)- }\end{array}$ & 84 & 8.66 & C33H48 & 93 & $35-54-1$ \\
\hline 4.56 & $\begin{array}{l}\text { 21H-Biline-8,12-dipropanoic acid, 2,17- } \\
\text { diethyl-1,2,3,4,5,19,23,24-octahydro-3,7,13,18- } \\
\text { tetramethyl-1,19-dioxo-, dimethyl ester, (2R,3R,4R)- }\end{array}$ & 81 & 6.49 & C35H46 & 18 & $89-77-3$ \\
\hline 4.56 & $\begin{array}{c}\text { Silane, } \\
\text { [(dichlorostannylene)dimethylidyne]tetrakis[trimethyl- }\end{array}$ & 79 & 5.21 & $\mathrm{Cl} 2 \mathrm{Si} 4 \mathrm{Sn}$ & 08 & $89-73-5$ \\
\hline 4.56 & $\begin{array}{l}\text { Spiro[isobenzofuran-1(3H),9'- } \\
{[9 \mathrm{H}] \text { xanthen]-3-one, } \quad 2 \text {-[1,3-dihydro-1-(4- }} \\
\text { methoxyphenyl)-3-oxo-1-isobenzofuranyl]- }\end{array}$ & 21 & .80 & $\mathrm{C} 35 \mathrm{H} 22$ & 38 & $17-71-0$ \\
\hline
\end{tabular}


Data File: 5-6

Curr Data Path:

Acquisition Date:

Run Time (min):

Vial:

Inj Vol $(\mu \mathrm{L})$ :

Scans:

Low Mass $(\mathrm{m} / \mathrm{z})$ :

High Mass ( $\mathrm{m} / \mathrm{z})$ :

Inst Method:

Proc Method:

RT: $0.00-35.02$ SM : 7G

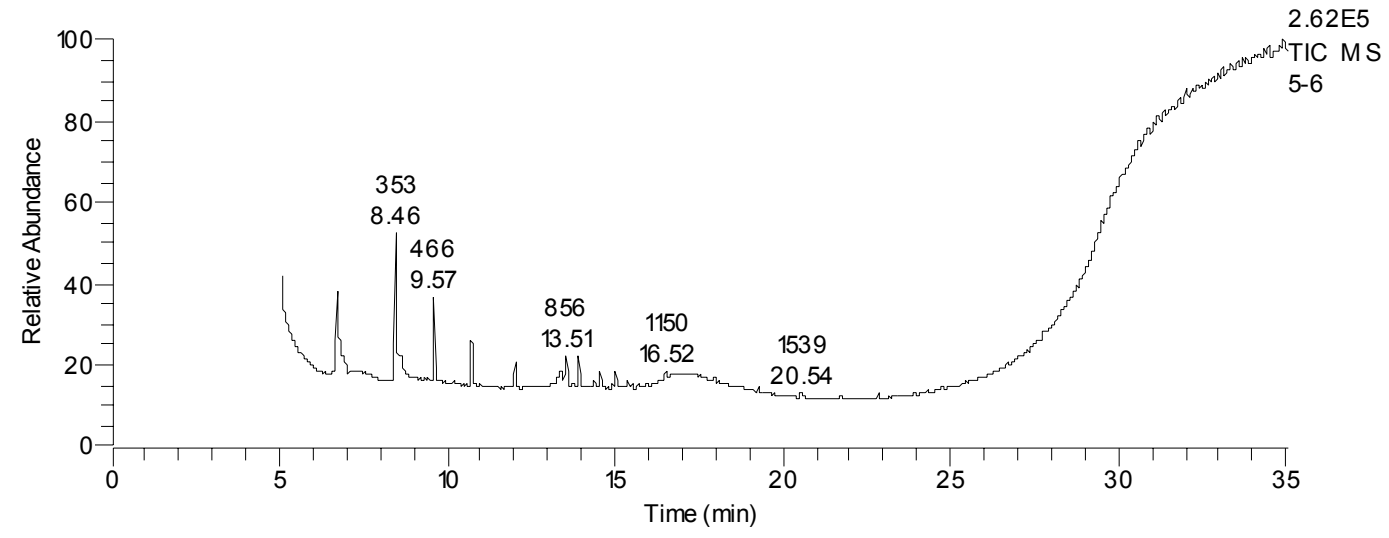

D:|Xcalibur|Data $\backslash G e m m a H \backslash p e p p e r s 100703 \backslash$

10/08/03 05:27:56

29.97

56

2.00

3024

35.00

550.00

D:|Xcalibur $\backslash$ methods $\mid$ pepper_PTV.meth

D: $|X c a l i b u r| m e t h o d s \backslash q u a l i t a t i v e I D$
$62 \mathrm{E} 5$

\begin{tabular}{|c|c|c|}
\hline RT & Peak Area & Area \% \\
\hline 6.73 & 419161 & 21.36 \\
\hline 7.14 & 33061 & 1.69 \\
\hline 7.36 & 71658 & 3.65 \\
\hline 8.46 & 499370 & 25.45 \\
\hline 9.31 & 818 & 0.04 \\
\hline 9.58 & 146813 & 7.48 \\
\hline 10.21 & 1476 & 0.08 \\
\hline 10.73 & 85025 & 4.33 \\
\hline 12.03 & 36556 & 1.86 \\
\hline 13.11 & 12552 & 0.64 \\
\hline 13.35 & 82530 & 4.21 \\
\hline 13.52 & 102853 & 5.24 \\
\hline 13.90 & 51714 & 2.64 \\
\hline 14.38 & 10629 & 0.54 \\
\hline 14.56 & 23750 & 1.21 \\
\hline 15.01 & 44436 & 2.26 \\
\hline 15.35 & 5441 & 0.28 \\
\hline 15.51 & 4641 & 0.24 \\
\hline 15.69 & 1750 & 0.09 \\
\hline 15.96 & 2214 & 0.11 \\
\hline 16.52 & 56429 & 2.88 \\
\hline
\end{tabular}




\begin{tabular}{|l|l|l|}
\hline 16.90 & 233271 & 11.89 \\
\hline 17.95 & 4638 & 0.24 \\
\hline 19.30 & 5125 & 0.26 \\
\hline 20.54 & 3436 & 0.18 \\
\hline 21.74 & 3267 & 0.17 \\
\hline 22.86 & 4473 & 0.23 \\
\hline 23.91 & 485 & 0.02 \\
\hline 24.78 & 2912 & 0.15 \\
\hline 25.45 & 2101 & 0.11 \\
\hline 25.82 & 2661 & 0.14 \\
\hline 26.69 & 3680 & 0.19 \\
\hline 27.78 & 3155 & 0.16 \\
\hline
\end{tabular}

\begin{tabular}{|c|c|c|c|c|c|c|}
\hline $\mathrm{T}$ & Name & I & rob. & Formula & W & Cas \\
\hline 0.21 & $\begin{array}{l}\text { Dihydrofuro[2,3-e]phenalene, 6-methoxy- } \\
\text { 8-oxo-2,3,3,10-tetramethyl-4,5,7-trihydroxy- }\end{array}$ & 17 & 3.02 & $\mathrm{C} 20 \mathrm{H} 20$ & 56 & NA \\
\hline 0.21 & Stearic acid, 3-(octadecyloxy)propyl ester & 02 & .89 & $\mathrm{C} 39 \mathrm{H} 78$ & 94 & $\begin{array}{ll} & 173 \\
67-40-7 & \end{array}$ \\
\hline 0.21 & Formyl colchicine & 95 & .04 & $\mathrm{C} 23 \mathrm{H} 25$ & 27 & $\mathrm{NA}$ \\
\hline 0.21 & \begin{tabular}{lr}
\multicolumn{1}{c}{ Acetic } & acid, \\
{$[$ bis $[($ trimethylsilyl)oxy $]$ phosphinyl $]-$,} & trimethylsilyl \\
ester &
\end{tabular} & 92 & .34 & O5PSi3 & 56 & $44-27-2$ \\
\hline 0.21 & $\begin{array}{l}\text { Fluoren-9-ol, } \\
\text { phenylethynyl)- }\end{array}$ & 91 & .13 & $\mathrm{C} 23 \mathrm{H} 18$ & 42 & $\mathrm{NA}$ \\
\hline
\end{tabular}


Data File:

$5-13$

Curr Data Path:

Acquisition Date:

Run Time (min):

Vial:

Inj Vol $(\mu \mathrm{L})$ :

Scans:

Low Mass (m/z):

High Mass ( $\mathrm{m} / \mathrm{z})$ :

Inst Method:

Proc Method:

RT: $0.00-35.01$ SM : $7 G$

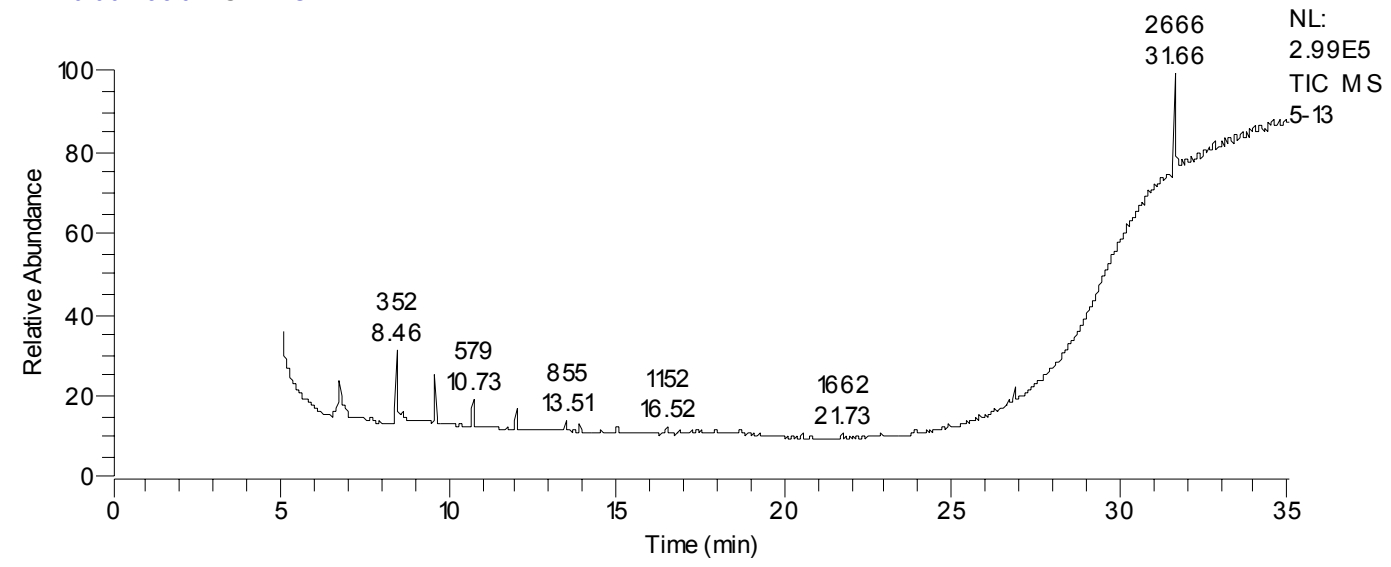

10/08/03 04:37:58

29.97

55

2.00

3035

35.00

550.00

D:|Xcalibur $\backslash$ methods $\mid$ pepper_PTV.meth

D: $\mid$ Xcalibur $\backslash$ methods $\backslash$ qualitativeID
D:|Xcalibur|Data $\backslash$ GemmaH $\backslash$ peppers $100703 \backslash$

\begin{tabular}{|c|c|c|}
\hline RT & Peak Area & Area \% \\
\hline 6.74 & 246064 & 28.07 \\
\hline 7.48 & 964 & 0.11 \\
\hline 7.70 & 4195 & 0.48 \\
\hline 8.46 & 247064 & 28.19 \\
\hline 9.32 & 2964 & 0.34 \\
\hline 9.58 & 95242 & 10.87 \\
\hline 10.73 & 48097 & 5.49 \\
\hline 12.02 & 32848 & 3.75 \\
\hline 13.07 & 1918 & 0.22 \\
\hline 13.35 & 4386 & 0.50 \\
\hline 13.51 & 23540 & 2.69 \\
\hline 13.90 & 11480 & 1.31 \\
\hline 15.02 & 13358 & 1.52 \\
\hline 15.19 & 661 & 0.08 \\
\hline 15.94 & 1223 & 0.14 \\
\hline 16.52 & 9106 & 1.04 \\
\hline 16.89 & 11972 & 1.37 \\
\hline 17.24 & 5921 & 0.68 \\
\hline 17.40 & 1926 & 0.22 \\
\hline 17.95 & 5584 & 0.64 \\
\hline 18.66 & 20098 & 2.29 \\
\hline
\end{tabular}




\begin{tabular}{|l|l|l|}
\hline 18.91 & 1578 & 0.18 \\
\hline 19.29 & 3566 & 0.41 \\
\hline 20.55 & 3525 & 0.40 \\
\hline 21.73 & 6996 & 0.80 \\
\hline 22.87 & 5629 & 0.64 \\
\hline 23.92 & 6678 & 0.76 \\
\hline 24.90 & 7876 & 0.90 \\
\hline 25.45 & 1361 & 0.16 \\
\hline 25.83 & 3253 & 0.37 \\
\hline 26.25 & 11461 & 1.31 \\
\hline 26.70 & 4427 & 0.51 \\
\hline 26.88 & 24464 & 2.79 \\
\hline 27.52 & 2921 & 0.33 \\
\hline 27.77 & 4214 & 0.48 \\
\hline
\end{tabular}

\begin{tabular}{|c|c|c|c|c|c|c|}
\hline RT & Name & I & rob. & Formula & W & Cas \\
\hline 6.89 & $\begin{array}{l}\text { 3-Pyridinecarboxylic acid, 2,7,10-tris(acetyloxy)- } \\
\text { 1,1a,2,3,4,6,7,10,11,11a-decahydro-1,1,3,6,9-pentamethyl-4- } \\
\text { oxo-4a,7a-epoxy-5H-cyclopenta[a]cyclopropa[f]cycloundecen- } \\
\text { 11-yl ester, } \\
\left.\left(1 \mathrm{aR}^{*}, 2 \mathrm{R}^{*}, 3 \mathrm{~S}^{*}, 4 \mathrm{aR}^{*}, 6 \mathrm{~S}^{*}, 7 \mathrm{~S}^{*}, 7 \mathrm{aS}^{*}, 8 \mathrm{E}, 10 \mathrm{R}^{*}, 11 \mathrm{R}^{*}, 11 \mathrm{aS} \mathrm{S}^{*}\right)\right]-\end{array}$ & 69 & 2.52 & C32H39 & 97 & $06-00-4$ \\
\hline 6.89 & $\begin{array}{l}\text { Hexadecanoic acid, 1a,2,5,5a,6,9,10,10a-octahydro- } \\
\text { 5,5a-dihydroxy-4-(hydroxymethyl)-1,1,7,9-tetramethyl-11-oxo- } \\
\text { 1H-2,8a-methanocyclopenta[a]cyclopropa[e]cyclodecen-6-yl } \\
\text { ester, [1aR-(1aà,2à,5á,5aá,6á,8aà,9à,10aà)]- }\end{array}$ & 64 & 0.09 & $\mathrm{C} 36 \mathrm{H} 58$ & 86 & $57-26-3$ \\
\hline 6.89 & Tetradecanoic acid, 12-methyl-, methyl ester & 46 & .20 & $\mathrm{C} 16 \mathrm{H} 32$ & 56 & $9-66-8$ \\
\hline 6.89 & 2-Hexyldecanoic acid & 40 & .09 & $\mathrm{C} 16 \mathrm{H} 32$ & 56 & $54-97-6$ \\
\hline 6.89 & $\begin{array}{l}\text { Pregnan-20-one, 3-(acetyloxy)-5,6-epoxy-6-methyl-, } \\
\text { cyclic 20-(1,2-ethanediyl acetal), (3á,5á,6á)- }\end{array}$ & 39 & .93 & $\mathrm{C} 26 \mathrm{H} 40$ & 32 & $84-25-9$ \\
\hline
\end{tabular}

\begin{tabular}{|c|c|c|c|c|c|c|}
\hline $\mathrm{T}$ & Name & I & rob. & la & W & $\begin{array}{rr} & \text { Cas } \\
\text { \# } & \end{array}$ \\
\hline 7.40 & $\begin{array}{c}\text { (22R)-6á,11á,21-Trihydroxy-16à,17à- } \\
\text { propylmethylenedioxypregna-1,4-diene-3,20-dione }\end{array}$ & 93 & .93 & $\begin{array}{ll} & \mathrm{C} 25 \mathrm{H} \\
34 \mathrm{O} 7 & \end{array}$ & 46 & NA \\
\hline 7.40 & $\begin{array}{c}\text { (22S)-6á,11á,21-Trihydroxy-16à,17à- } \\
\text { propylmethylenedioxypregna-1,4-diene-3,20-dione }\end{array}$ & 88 & .20 & $\begin{array}{ll} & \mathrm{C} 25 \mathrm{H} \\
34 \mathrm{O} 7 & \end{array}$ & 46 & NA \\
\hline 7.40 & $\begin{array}{l}\text { 3,9-Epoxypregn-16-ene-14-18-diol-20-one, } \\
\text { 7,11-diacetoxy-3-methoxy- }\end{array}$ & 79 & .22 & $\mathrm{C} 26 \mathrm{H}$ & 92 & NA \\
\hline 7.40 & $\begin{array}{c}\text { (22S)-6à,11á,21-Trihydroxy-16à,17à- } \\
\text { propylmethylenedioxypregna-1,4-diene-3,20-dione }\end{array}$ & 78 & .02 & $\mathrm{C} 25 \mathrm{H}$ & 46 & $61-53-1$ \\
\hline 7.40 & Demecolcine & 74 & .24 & $25 \mathrm{NO5}$ & 71 & $30-5$ \\
\hline
\end{tabular}

\begin{tabular}{|l|l|l|l|l|l|l|}
\hline & Name & & & For & & Cas \\
\hline
\end{tabular}




\begin{tabular}{|c|c|c|c|c|c|c|}
\hline $\mathrm{T}$ & & I & rob. & mula & W & \# \\
\hline 8.66 & $\begin{array}{l}\text { 9,12,15-Octadecatrienoic } \quad \text { acid, } \\
\text { dihydroxypropyl ester, (Z,Z,Z)- }\end{array}$ & 08 & .42 & $\mathrm{H} 36 \mathrm{O} 4$ & 52 & $65-99-1$ \\
\hline 8.66 & $\begin{array}{l}\text { Nonanoic acid, } \\
\text { hexenylidenecyclopropylidene)-, } \\
\text { (hydroxymethyl)ethyl ester, (Z,Z,Z)- }\end{array}$ & 03 & .18 & $\mathrm{H} 36 \mathrm{O} 4$ & 52 & $68-58-1$ \\
\hline 8.66 & $\begin{array}{l}\text { 9,12-Octadecadienoic acid, methyl ester, } \\
(\mathrm{E}, \mathrm{E})-\end{array}$ & 02 & .98 & $\mathrm{H} 34 \mathrm{O} 2$ & 94 & $6-97-4$ \\
\hline 8.66 & Cyclooctenone, dimer & 98 & .20 & $\mathrm{H} 24 \mathrm{O} 2$ & 48 & $19-51-0$ \\
\hline 8.66 & $\begin{array}{l}\text { 9,11-Octadecadienoic acid, methyl ester, } \\
(\mathrm{E}, \mathrm{E})-\end{array}$ & 96 & .88 & $\mathrm{H} 34 \mathrm{O} 2$ & 94 & $38-47-6$ \\
\hline
\end{tabular}

\begin{tabular}{|c|c|c|c|c|c|c|c|}
\hline $\mathrm{T}$ & Name & I & rob. & $\begin{array}{l}\text { Formu } \\
\text { la }\end{array}$ & W & \# & Cas \\
\hline 8.91 & $\begin{array}{l}\text { Dodecanoic acid, 1a,2,5,5a,6,9,10,10a- } \\
\text { octahydro-5a-hydroxy-4-(hydroxymethyl)-1,1,7,9- } \\
\text { tetramethyl-6,11-dioxo-1H-2,8a- } \\
\text { methanocyclopenta[a]cyclopropa[e]cyclodecen-5-yl } \\
\text { ester, [1aR-(1aà,2à,5á,5aá,8aà,9à,10aà)]- }\end{array}$ & 44 & 5.68 & $\mathrm{C} 32 \mathrm{H}$ & 28 & $08-68-0$ & 775 \\
\hline 8.91 & $\begin{array}{l}\text { Hexadecanoic acid, 1a,2,5,5a,6,9,10,10a- } \\
\text { octahydro-5,5a-dihydroxy-4-(hydroxymethyl)-1,1,7,9- } \\
\text { tetramethyl-11-oxo-1H-2,8a- } \\
\text { methanocyclopenta[a]cyclopropa[e]cyclodecen-6-yl } \\
\text { ester, [1aR-(1aà,2à,5á,5aá,6á,8aà,9à,10aà)]- }\end{array}$ & 43 & 5.07 & $\mathrm{C} 36 \mathrm{H}$ & 86 & $57-26-3$ & 525 \\
\hline 8.91 & 4'-Apo-á,.psi.-carotenoic acid & 43 & 5.07 & $46 \mathrm{O} 2$ & 98 & $8-88-4$ & 246 \\
\hline 8.91 & $\begin{array}{ccc}\text { Hexadecanoic } & \text { acid, } & \text { N,N- } \\
\text { bis }[(\text { methylcarboxy)ethyl-2-(2-butoxyethoxy) }]- & \end{array}$ & 18 & .59 & $69 \mathrm{NO} 9$ & 59 & & NA \\
\hline 8.91 & $\begin{array}{l}\text { Octadecanoic } \text { acid, } 2 \text { 2-hydroxy-1,3- } \\
\text { propanediyl ester }\end{array}$ & 13 & .70 & $76 \mathrm{O} 5$ & 24 & $40-5$ & $504-$ \\
\hline
\end{tabular}




\begin{tabular}{|c|c|c|c|c|c|c|}
\hline $\mathrm{T}$ & Name & I & rob. & $\begin{array}{ll} & \text { Formul } \\
\text { a }\end{array}$ & W & $\begin{array}{ll} & \text { Cas } \\
& \end{array}$ \\
\hline 6.88 & Stigmast-5-en-3-ol, oleate & 30 & 3.79 & $\begin{array}{ll}\mathrm{O} 2 & \mathrm{C} 47 \mathrm{H} 8 \\
2 \mathrm{O} & \end{array}$ & 78 & NA \\
\hline 6.88 & Stigmastan-3,5-dien & 21 & 7.27 & $\begin{array}{ll} & \mathrm{C} 29 \mathrm{H} 4 \\
8 & \end{array}$ & 96 & NA \\
\hline 6.88 & Stigmastan-3-ol, 5-chloro-, acetate, (3á,5à)- & 16 & 3.92 & $\begin{array}{ll}\mathrm{C} 31 \mathrm{H} 5 \\
3 \mathrm{ClO} 2\end{array}$ & 92 & $24-19-1$ \\
\hline 6.88 & Sitosterol acetate & 13 & 2.30 & $\mathrm{C} 31 \mathrm{H} 5$ & 56 & NA \\
\hline 6.88 & á-Sitosterol acetate & 02 & .43 & C31H5 & 56 & $915-$ \\
\hline
\end{tabular}

